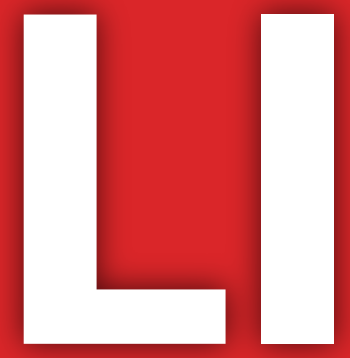

\title{
LABORATORY INVESTIGATION
}

THE BASIC AND TRANSLATIONAL PATHOLOGY RESEARCH JOURNAL VOLUME 99 | SUPPLEMENT 1 | MARCH 2019

\section{※USCAP 2019}

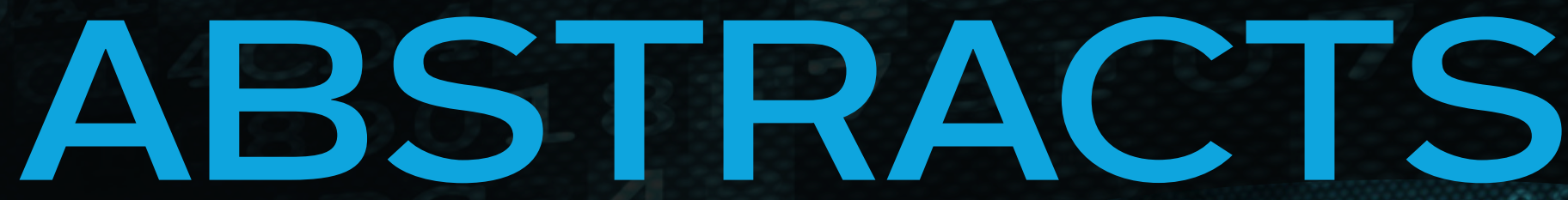

INFECTIOUS DISEASE PATHOLOGY

(1435-1462)

USCAP 108TH ANNUAL MEETING

JNLOCKING

IYOURINGENUTIY

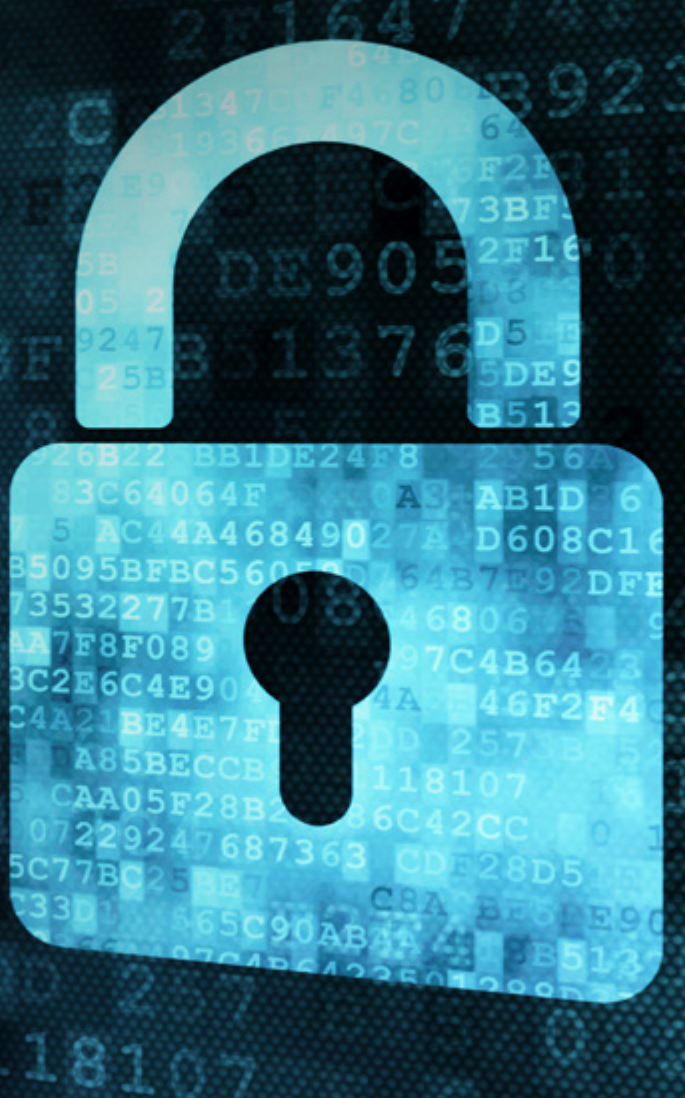

MARCH 16-21, 2019

National Harbor, Maryland Gaylord National Resort \& Convention Center 


\section{EDUCATION COMMITTEE}

Jason L. Hornick, Chair

Rhonda K. Yantiss, Chair, Abstract Review Board and Assignment Committee

Laura W. Lamps, Chair, CME Subcommittee

Steven D. Billings, Interactive Microscopy Subcommittee

Shree G. Sharma, Informatics Subcommittee

Raja R. Seethala, Short Course Coordinator

Ilan Weinreb, Subcommittee for Unique Live Course Offerings

David B. Kaminsky (Ex-Officio)

Aleodor (Doru) Andea

Zubair Baloch

Olca Basturk

Gregory R. Bean, Pathologist-in-Training

$$
\text { Daniel J. Brat }
$$

Ashley M. Cimino-Mathews
James R. Cook

Sarah M. Dry

William C. Faquin

Carol F. Farver

Yuri Fedoriw

Meera R. Hameed

Michelle S. Hirsch

Lakshmi Priya Kunju

Anna Marie Mulligan

Rish Pai

Vinita Parkash

Anil Parwani

Deepa Patil

Kwun Wah Wen, Pathologist-in-Training

\section{ABSTRACT REVIEW BOARD}

Benjamin Adam

Michelle Afkhami

Narasimhan (Narsi) Agaram

Rouba Ali-Fehmi

Ghassan Allo

Isabel Alvarado-Cabrero

Christina Arnold

Rohit Bhargava

Justin Bishop

Jennifer Boland

Elena Brachtel Marilyn Bui

Shelley Caltharp

Joanna Chan

Jennifer Chapman Hui Chen

Yingbei Chen

Benjamin Chen

Rebecca Chernock Beth Clark

James Conner

Alejandro Contreras Claudiu Cotta

Timothy D'Alfonso

Farbod Darvishian Jessica Davis

Heather Dawson

Elizabeth Demicco

Suzanne Dintzis

Michelle Downes Daniel Dye

Andrew Evans

Michael Feely

Dennis Firchau

Larissa Furtado

Anthony Gill

Ryan Gill

Paula Gintar
Tamara Giorgadze

Raul Gonzalez

Purva Gopal

Anuradha Gopalan

Jennifer Gordetsky

Rondell Graham

Alejandro Gru

Nilesh Gupta

Mamta Gupta

Krisztina Hanley

Douglas Hartman Yael Heher

Walter Henricks

John Higgins

Mai Hoang

Mojgan Hosseini

Aaron Huber

Peter Illei

Doina Ivan

Wei Jiang

Vickie Jo

Kirk Jones

Neerja Kambham

Chiah Sui (Sunny) Kao

Dipti Karamchandani Darcy Kerr

Ashraf Khan

Rebecca King

Michael Kluk

Kristine Konopka

Gregor Krings

Asangi Kumarapeli

Alvaro Laga

Cheng-Han Lee

Zaibo Li

Haiyan Liu

Xiuli Liu

Yan-Chun Liu
Tamara Lotan

Anthony Magliocco Kruti Maniar

Jonathan Marotti

Emily Mason

Jerri McLemore

Bruce McManus

David Meredith Anne Mills

Neda Moatamed

Sara Monaco

Atis Muehlenbachs

Bita Naini

Dianna Ng

Tony Ng

Ericka Olgaard

Jacqueline Parai

Yan Peng

David Pisapia

Alexandros Polydorides

Sonam Prakash

Manju Prasad

Peter Pytel

Joseph Rabban

Stanley Radio

Emad Rakha

Preetha Ramalingam

Priya Rao

Robyn Reed

Michelle Reid

Natasha Rekhtman

Michael Rivera

Michael Roh

Andres Roma

Avi Rosenberg

Esther (Diana) Rossi

Peter Sadow

Safia Salaria
Steven Salvatore

Souzan Sanati

Sandro Santagata Anjali Saqi

Frank Schneider

Jeanne Shen Jiaqi Shi

Wun-Ju Shieh

Gabriel Sica

Deepika Sirohi

Kalliopi Siziopikou

Lauren Smith

Sara Szabo

Julie Teruya-Feldstein

Gaetano Thiene

Khin Thway

Rashmi Tondon

Jose Torrealba

Evi Vakiani

Christopher Vanden Bussche

Sonal Varma

Endi Wang

Christopher Weber

Olga Weinberg

Sara Wobker

Mina Xu

Shaofeng Yan

Anjana Yeldandi

Akihiko Yoshida

Gloria Young

Minghao Zhong

Yaolin Zhou

Hongfa Zhu

Debra Zynger 


\section{Tissue Schistosomiasis, A Still Relevant but Neglected Tropical Disease, Case Series}

Patrick Akakpo' ${ }^{1}$, Leonard Derkyi-Kwarteng, Emmanuel Imbeah²

${ }^{1}$ University of Cape Coast, Cape Coast, Ghana, ${ }^{2}$ A.C.T Diagnostics, Cape Coast, Ghana

Disclosures: Patrick Akakpo: None; Leonard Derkyi-Kwarteng: None; Emmanuel Imbeah: None

Background: Schistosoma infection is geographically widespread with a relatively low mortality rate, but a high morbidity rate, causing severe debilitating illness in millions of people worldwide. The disease is often associated with water resource development projects, such as dams where the snail intermediate hosts (Bulinus species) of the parasite breed. We present three cases to raise awareness of the continued existence of tissue schistosomiasis. Infestation may present acutely or insidiously with often debilitating consequences in many organs.

Design: Case 1: A 35year old man died within 12 hours of admission to the ER for chest pain. Autopsy showed a left ventricular failure from hypertensive heart disease resulting from chronic pyelonephritis from bilateral hydronephrosis and hydroureters from bilateral ureteric stenosis from chronic urinary Schistosoma haematobium infestation evidenced by numerous calcified Schistosoma haematobium ova with surrounding extensive chronic granulomatous inflammatory changes with intense fibrosis of the ureters. Fig 1. Case 2: A 14-year-old female presented with prolapsed sessile anorectal polyp. Biopsy diagnosed an ulcerated, polypoid, inflammatory mass, with a core of Schistosoma haematobium ova surrounded by an intense infiltrate of eosinophils, admixed with plasma cells and lymphocytes. There were eosinophil mucosal and crypt abscesses surrounding Schistosoma haematobium ova. Fig 2 (top) Case 3: A 16-year-old boy had an appendicectomy for acute appendicitis. Histopathological examination of the appendix showed extensive transmural eosinophil dominated acute inflammation with eosinophil abscesses superimposed on chronic granulomatous inflammation to Schistosoma haematobium ova. A diagnosis of Schistosoma haematobium related acute appendicitis was made. Figure 2 (bottom)

Results: Two patients presented acutely and required urgent care. Their histopathological picture was acute and dominated by eosinophil abscesses. The urinary tract infestation was however chronic and insidious and sadly resulted in a mortality. The wide variation in age of patients underscores the difficult epidemiology of schistosomiasis infestations.
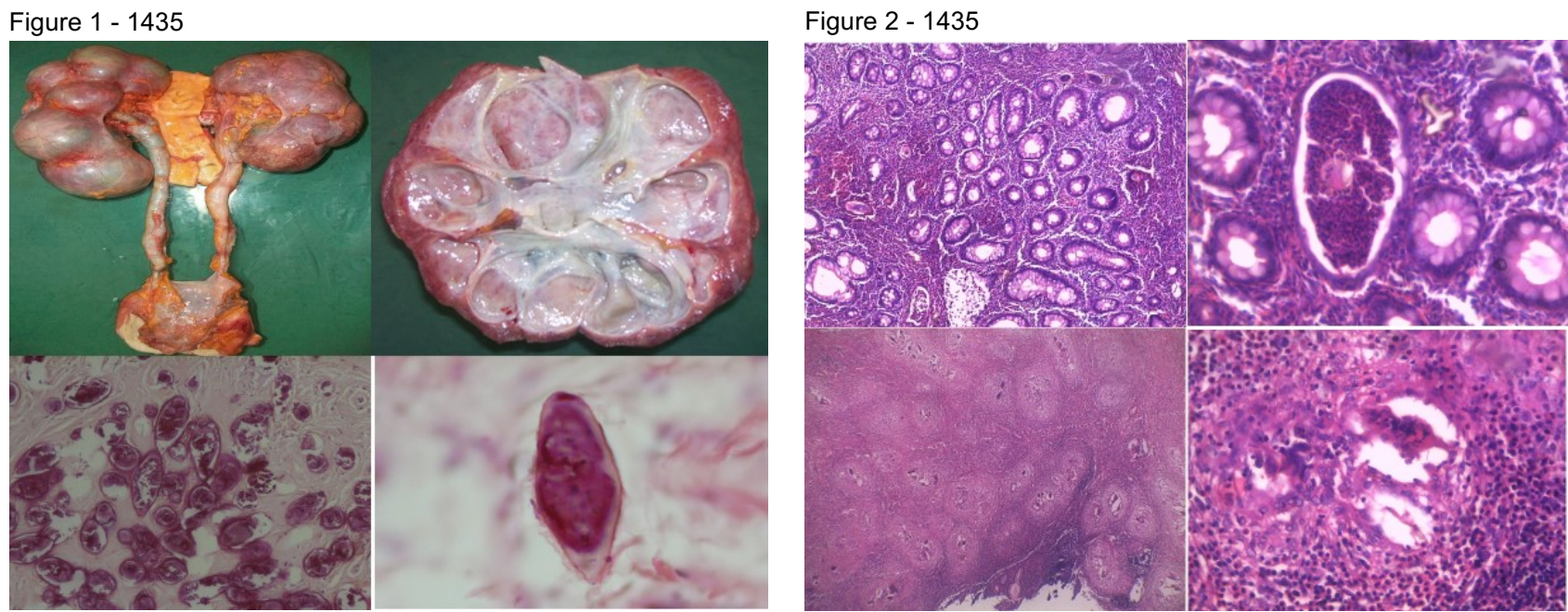

Conclusions: tissue schistosomiasis is still an important cause of morbidity and mortality in endemic areas. Physicians practising in countries favored by migrants must be aware of the possibility of seeing atypical presentations of parasitic diseases, in the light of worldwide increase in immigration and tourism.

\section{Anal Canal Squamous Cell Carcinoma. Clinicopathologic Aspects and Prevalence of Human Papilloma Virus}

Isabel Alvarado-Cabrero' ${ }^{1}$, Rafael Estevez-Castro², Patricia Piña-Sánchez ${ }^{3}$, Raquel Valencia-Cedillo ${ }^{4}$

${ }^{1}$ Mexican Oncology Hospital IMSS, Mexico, MEX, Mexico, ${ }^{2}$ Laboratorio de Patologia Dra. Rosario Castro, Santiago, Dominican

Republic, ${ }^{3}$ Mexican Oncology Hospital IMSS, Mexico City, DF, Mexico, ${ }^{4}$ Mexican Oncology Hospital IMSS, Cd Mexico, MEX, Mexico

Disclosures: Isabel Alvarado-Cabrero: None; Rafael Estevez-Castro: None; Patricia Piña-Sánchez: None; Raquel Valencia-Cedillo: None 
Background: Squamous Cell Carcinoma (SCC) of the Anal Canal (AC) incidence has been increasing over the past several decades and is higher in women than in men. Infection with high risk (HR) Human Papilloma Virus (HPV) is strongly associated with AC SCC.

Our aim is to examine associations between the clinicopathologic characteristics of patients according to HPV status.

Design: Retrospective study of 1,250 invasive AC SCC diagnosed between 2000 and 2017 in our institution. Clinical and sociodemographic data were collected from the respective medical files. Paraffin blocks were tested for the presence of HPV DNA by in situ hybridization and/or the p16 oncoprotein by immunohistochemistry.

Results: Among the 1,250 patients with AC SCC, 887 (71\%) were women. Median age at diagnosis was 58 years. Thirty-five percent of women had previous history of cervical intraepithelial neoplasia and $25 \%$ of men had a strong ( $>30$ pack-year) tobacco history. Of the 680 cases reviewed, $652(96 \%)$ had detectable HPV. HPV 16 was the most frequent type detected.

High grade anal intraepithelial neoplasia (HGAIN) was found in $65 \%$ of the surgical specimens.

Conclusions: Most patients included in the present study were female (71\%). HPV was present in 652 of 680 (96\%) samples analyzed.

AC SCC was preceded by HGAIN in $65 \%$ of the cases. The results of this study demonstrate the evolving importance of anal HPV-related pathology and cancer among women.

\section{Immunohistochemical Co-Localization Of Poly [ADP-Ribose] Polymerase (PARP)-1, Cyclooxygenase (COX)-2, And Phosphatase And Tensin Homolog (PTEN) In Schistosomal Urinary Carcinoma: Targeted Therapy For Endemic Disease?}

Rania Aly ${ }^{1}$, Waleed Dawood ${ }^{1}$, Rasha Elsaka ${ }^{1}$

${ }^{1}$ Alexandria University, Alexandria, Egypt

Disclosures: Rania Aly: None; Waleed Dawood: None; Rasha Elsaka: None

Background: Schistosomiasis, endemic in many countries, is an important risk factor of urinary bladder carcinoma. While PARP-1 is related to tumorogenesis and became an important molecule for targeted therapy, PTEN is responsible of DNA repair. COX-2 is an angiogenic factor playing a fundamental role in inflammation-related tumorogenesis. The aim of the current study is to investigate the colocalization of these markers in Schistosomal-positive urinary carcinoma in comparison to non-Schistosomal carcinoma, their prognostic impact and if targeted therapy is useful in this endemic disease.

Design: The retrospective study cohort included 100 cystectomies, operated in Alexandria University Hospital, Egypt, between the years 2000-2012. The cohort included 30 Schistosomal-positive cases and 70 non-Schistosomal cases. Twenty cases were invasive squamous cell carcinomas and 80 cases were transitional carcinomas. Ten normal urothelial tissue samples were used as controls.

Immunohistochemistry was done using Strepatavidin-biotin method, co-localization image analysis and scoring of each marker was done using the quick (Q) score (Leica, Germany). Follow-up of the cases for 5-year cumulative incidence of recurrence (CIR) and cancer-specific death was retrieved from the medical archive of the clinical oncology department of Alexandria University Hospital.

Results: PARP-1 and COX-2 scorings were increased in all carcinoma cases compared to the normal bladder tissue samples, and were co-localized. While, PTEN was lost in carcinomas compared to the normal tissue samples. Schistosomal-positive tumors were found to have higher expression of PARP-1 and COX-2 compared to non-Schistosomal cases and showed lower PTEN $(p=0.001)$ (figure 1). In squamous cell carcinomas, the expression of PARP-1 and COX-2 was higher than in transitional carcinomas $(p=0.04)$. The Schistosomalpositive cases showed significant higher CIR and cancer-specific death. 
Figure $1-1437$

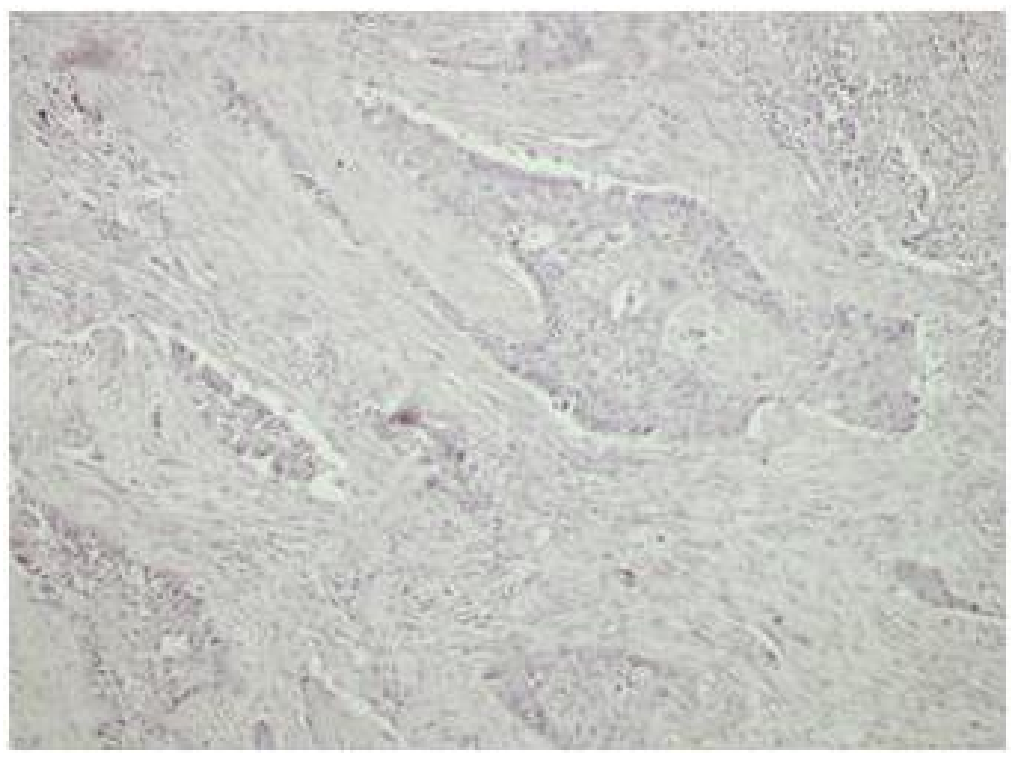

Conclusions: Schistosomal-positive urinary carcinoma shows remarkable PTEN loss compared to the non-Schistosomal cases. Schistosomal-positive urinary carcinoma mediates an inflammatory milieu with increased PARP-1 and COX-2 expression, the former known to have targeted therapy, indicating its prognostic as well as predictive role which could be helpful in this endemic disease.

\section{Clinicohistopathologic Correlation Between Stool Parasite Testing and Gastrointestinal Mucosal Biopsies \\ Juliana Andrici ${ }^{1}$, Christopher Hergott ${ }^{1}$, Alvaro Laga ${ }^{1}$, Jason Hornick ${ }^{2}$, Isaac Solomon ${ }^{1}$ \\ ${ }^{1}$ Brigham and Women's Hospital, Boston, MA, ${ }^{2}$ Brigham and Women's Hospital, Harvard Medical School, Boston, MA}

Disclosures: Juliana Andrici: None; Christopher Hergott: None; Alvaro Laga: None; Jason Hornick: None; Isaac Solomon: None

Background: A wide variety of parasites can infect the gastrointestinal (GI) tract, resulting in severe diarrhea, anemia, and weight loss. While HIV-related infections have decreased in the late HAART era, the range of organisms associated with immunomodulatory therapies for cancer and autoimmune diseases continues to expand. The gold standard for diagnosis is direct visualization of organisms in stool specimens, which can be aided by antigen testing, and endoscopic mucosal biopsies. The spectrum of histologic findings associated with intestinal parasitic infections in the current era is poorly described.

Design: Stool ova and parasite (O\&P) examination and Giardia/Cryptosporidium (G/C) antigen tests were reviewed at an academic medical center with a large cancer and transplant population. Patients with endoscopic GI biopsies performed within six months of stool parasite testing were identified, and cases with positive laboratory findings and representative negative controls were histologically reviewed for the number of intraepithelial lymphocytes (IELs), number of lamina propria eosinophils, and the presence of granulomata, neutrophils, and parasites.

Results: Over a 10-year period (2008-2018), 19,084 stool O\&P exams and 2,274 G/C antigen tests were performed on 14,368 individual patients. A total of $343(1.7 \%)$ positive results from 249 patients were identified, representing 117 infections with at least one pathogenic parasite (66 Giardia, 17 Strongyloides, 9 Cryptosporidium, 9 Entamoeba histolytica, 7 Cyclospora, and 11 assorted helminths) and 132 cases with non-pathogenic organisms (e.g., Blastocystis, E. coli, Endolimax). Within 6 months of laboratory testing, 3,368 biopsies were performed on 2,797 patients, including 33 associated with positive stool parasite testing (10 pathogenic). Findings in positive and negative cases included mild to severe active chronic enteritis and colitis, increased IELs, and granulomata, with 13 infections identified on biopsies with negative stool testing. 


\begin{tabular}{|c|c|c|c|}
\hline Characteristic & $\begin{array}{c}\text { Pathogenic organism on } \\
\text { stool sample }\end{array}$ & $\begin{array}{c}\text { Non-pathogenic organism } \\
\text { on stool sample }\end{array}$ & Negative stool sample \\
\hline Paired biopsies and stool sample (n)* & 10 & 23 & 3335 \\
\hline Pathology report ${ }^{* *}$ & $\mathbf{N}=10$ & $\mathbf{N}=\mathbf{2 3}$ & $\mathbf{N}=713$ \\
\hline Histology within normal limits (n, \%) & $2(20)$ & $7(30)$ & $212(30)$ \\
\hline Active inflammation (n, \%) & $5(50)$ & $7(30)$ & $263(37)$ \\
\hline Chronic inflammation (n, \%) & $0(0)$ & $7(30)$ & $181(25)$ \\
\hline Graft versus host disease $(n, \%)$ & $0(0)$ & $0(0)$ & $55(8)$ \\
\hline Granulomata $(\mathrm{n}, \%)$ & $3(33)$ & $0(0)$ & $13(2)$ \\
\hline Organisms $(\mathrm{n}, \%)$ & $0(0)$ & $0(0)$ & $2(0.3)^{\star * *}$ \\
\hline $\begin{array}{l}\text { Histology review of duodenum or colon } \\
\text { biopsies }\end{array}$ & $N=6$ & $N=7$ & $N=13$ \\
\hline n & 2.5 & 2.2 & 3.8 \\
\hline $\begin{array}{l}\text { Number of eosinophils per HPF, n } \\
\text { (range) }\end{array}$ & $24(7-45)$ & $16(1-74)$ & $17(3-60)$ \\
\hline Neutrophils present $(\mathrm{n}, \%)$ & $4(67)$ & $3(43)$ & $7(54)$ \\
\hline Granuloma(s) present (n, \%) & $3(50)^{* * * *}$ & $1(14)$ & $0(0)$ \\
\hline Organisms $(n, \%)$ & $0(0)$ & $(0)$ & $1(8)^{\star \star *}$ \\
\hline \multicolumn{4}{|c|}{$\begin{array}{l}{ }^{*} \text { Biopsies included duodenum, ileum, other small bowel, and colon } \\
{ }^{* *} 20 \% \text { of negative cases were reviewed by report } \\
{ }^{* * *} \text { Trichuris trichiura } \\
{ }^{* * * *} \text { Three samples from a single patient with a history of leukemia, status post bone marrow transplant. } \\
\text { HPF: high-power field; IELs: intra-epithelial lymphocytes. }\end{array}$} \\
\hline
\end{tabular}

Conclusions: Parasitic infections of the GI tract were relatively uncommon, with a positive laboratory test in $1.7 \%$ of patients. Concurrent GI biopsies were obtained in $20 \%$ of patients and showed no significant difference in the inflammatory response on histologic review. Due to the lack of specificity of the biopsy findings, a low threshold should be used to recommend stool O\&P testing in cases of unexplained symptoms, particularly in immunosuppressed individuals.

\section{Human Papilomavirus (HPV) Genotype Distribution in Cervical Cancer-Free Colombian Women is Different From the Worldwide Pattern: Potential Implications for HPV Vaccine Program in Latin American}

Javier Baena-Del Valle ${ }^{1}$, Flor Diaz ${ }^{1}$, Luz Hernandez ${ }^{1}$, Rocio Lopez ${ }^{1}$, Paula A Rodriguez - Urrego ${ }^{2}$

${ }^{1}$ Fundacion Santa Fe de Bogota, Bogota, Colombia, ${ }^{2}$ University Hospital Fundacion Santa Fe de Bogota, Bogotà, Colombia

Disclosures: Javier Baena-Del Valle: None; Flor Diaz: None; Luz Hernandez: None; Rocio Lopez: None; Paula A Rodriguez - Urrego: None

Background: Cervical cancer is still an important cause of death from cancer in Latin America. Since HPV is known to cause almost all cervical cancers, vaccines have been developed and continuously improved to prevent carcinogenic HPV infections, especially those due genotypes 16 and 18. Few recent studies have shown that the high-risk HPV (HR-HPV) genotypes 16, 18 (contained in most vaccines), 31 , $33,45,52$ and 58 (contained in a new 9-valent vaccine) are not necessarily predominant in Latin America, raising concern about the potential efficacy of the HPV vaccine program in this population. The aim of this study was to determine the prevalence and distribution of HPV genotypes in a subpopulation of Colombian women screened for cervical cancer in Fundacion Santa Fe de Bogota University Hospital (Bogota, Colombia) in order to ensure the accuracy of HPV vaccines in the target population.

Design: Cervical swabs obtained from 1028 women aged 15 to 74 years old were included in this cross sectional study (2017 - Aug/2018). Samples were collected in BD SurePath ${ }^{\mathrm{TM}}$ Collection Vial and $69 \%$ had simultaneous BD SurePath ${ }^{\mathrm{TM}}$ liquid-based cytology (LBC). HPV detection and genotyping was performed by using HPV direct flow chip (master diagnostica).

Results: The prevalence of HPV was $33.1 \%$ (high-risk: $20.33 \%$, low-risk: $10.26 \%$ ). HR-HPV co-infections were found in $2.54 \%$. HR-HPV prevalence in women aged $15-20$ years was $40 \%$. HR-HPV was detected in $13 \%(n=63)$ of negative LBCs, $87 \%(n=45)$ of low-grade squamous intraepithelial lesion (LSIL) and $100 \%(n=10)$ of high-grade squamous intraepithelial lesion (HSIL). The most prevalent HRHPV types were $51(11.4 \%), 16(9.8 \%), 39(8.9 \%)$ and $66(8.9 \%) .71 .4 \%$ of patients that had HR-HPV not present in the non-9 valent vaccine had confirmed SIL (16\% had HSIL). Sensitivity and specificity of the HPV-test and LBC was $75 \%$ and $56 \%$, and $60 \%$ and $76 \%$ respectively.

Conclusions: We show that HR-HPV types were different than the ones included in the most recent 9-valent vaccine in $56.8 \%$ of all cases and $66.0 \%$ of women aged $15-20$ years, and they cause abnormal cytology and histology-demonstrated HSIL. Adding to a growing body of evidence that HPV genotype distribution in Latin America it is not similar to the distribution pattern seen in other parts of the world, thus affecting the potential vaccine impact in this population. 


\title{
1440 Comparision of BD Max and Biofire FilmArray GI Panel for GI Pathogen Detection in Patients of Infectious Diarrhea from a Large Community Hospital
}

Zhengshan Chen ${ }^{1}$, Christopher Upano ${ }^{1}$, Joycelyn Simley ${ }^{1}$, Susan Butler-Wu ${ }^{1}$

${ }^{1}$ LAC + USC Medical Center, Los Angeles, CA

Disclosures: Zhengshan Chen: None; Christopher Upano: None; Susan Butler-Wu: None

\begin{abstract}
Background: Infectious diarrhea is an important cause of morbidity and mortality worldwide. Traditional methods for the detection of gastrointestinal (GI) pathogens have limited sensitivity and are time-consuming to perform. Several rapid molecular assays for GI pathogens have been developed. In this study, we compared the performance of two FDA-cleared multiplex panels for GI pathogens in a large public health hospital. The BD Max targets 11 pathogens ( 8 bacteria and 3 parasites) over three distinct panels. The FilmArray GI Panel targets 22 pathogens in one panel (13 bacteria, 5 viruses, and 4 parasites).
\end{abstract}

Design: 100 prospective stool samples submitted to our laboratory for routine stool testing were simultaneously tested in a blinded fashion by BD Max and FilmArray GI Panel. Discordant results between BD Max and FilmArray GI Panel were subjected to result arbitration by additional testing where available. We assessed provider adherence to recommended clinical practice guidelines for the ordering of stool testing using both American College of Gastroenterology (ACG, 2016) and Infectious Disease Society of America (IDSA, 2017) guidelines.

Results: Among 100 samples, $69 \%$ met ACG guidelines for testing, with only $57 \%$ meeting IDSA guidelines for testing. Routine test methods were positive for GI pathogens in 10 (10\%) samples, compared to 16 (16\%) with BD Max and 43 (43\%) by FilmArray GI Panel. BD Max had a sensitivity of $93.8 \%$ and a specificity of $100 \%$, with the majority of false-negative results occurring with the extended enteric bacterial panel. In contrast, FilmArray GI Panel had a sensitivity of $100 \%$ but a specificity of $93 \%$. All patients positive for pathogens detectable by both BD Max and FilmArray GI Panel met clinical criteria for testing. However, only 54.5\% (12/22) of patients positive for organisms only detectable by FilmArray GI Panel (e.g. enteropathogenic Escherichia coli) met clinical criteria for testing. Of the 10 patients with toxigenic $C$. difficile detected by FilmArray GI Panel, only 4 met clinical criteria for testing.

Conclusions: Both BD Max and FilmArray GI Panel yielded increased positive GI pathogens detection compared to routine testing methods. BD Max appeared to lack sensitivity with extended enteric bacterial panel, whereas FilmArray GI Panel had decreased specificity. The FilmArray GI Panel detected possible stool pathogens in patients who did not meet clinical criteria for testing. Judicious use of ordering of large multiplex stool panels is therefore necessary.

\section{Clinical Performance of Mycobacterial Immunohistochemistry: Beginning of the End of Ziehl- Neelsen?}

Jessica Crothers ${ }^{1}$, Alvaro Laga ${ }^{1}$, Isaac Solomon ${ }^{1}$

${ }^{1}$ Brigham and Women's Hospital, Boston, MA

Disclosures: Jessica Crothers: None; Alvaro Laga: None; Isaac Solomon: None

Background: Diagnosis of mycobacterial infections poses significant challenges in the clinical and anatomic laboratories. In anatomic specimens, histochemical stains (acid fast bacilli [AFB], modified acid-fast bacilli [mAFB]) are often used in the context of characteristic inflammatory patterns, but sensitivity is low and evaluation time-consuming. We recently reported the use of an immunohistochemical (IHC) anti-mycobacteria antibody(CP140; Biocare medical, Concord CA at a 1:500 dilution) as a sensitive, efficient screening tool. Following clinical validation, we assessed the performance of this new test amongst general, noninfectious disease-trained anatomic pathologists.

Design: All cases in which mycobacterial IHC was ordered during routine diagnostic work-up were retrospectively identified. Results were derived from the finalized pathology report and compared to a composite reference standard in which demonstration of organisms by histochemical stains or isolation in culture was considered positive.

Results: From October 2017 to September 2018, mycobacterial IHC was ordered on 79 cases by 25 unique pathologists. These cases represented 70 patients and the majority were pulmonary $(47,59.5 \%)$ or from lymph nodes $(11,13.9 \%)$. Fifty-eight cases $(73.4 \%)$ had granulomatous inflammation, $10(12.7 \%)$ abscess formation, and $12(15.2 \%)$ showed acute and/or chronic inflammation. Concurrent AFB cultures were obtained for 51 (64.6\%) cases. AFB staining was performed on 71 (89.8\%), and mAFB staining on 44 (55.7\%) cases. Fortyone cases $(51.9 \%)$ had concurrent AFB, mAFB and mycobacterial IHC.

Thirty-six cases (44.3\%) were considered positive. The sensitivity and specificity of mycobacteria IHC was $45.71 \%$ and $97.7 \%$. In cases that also included AFB and/or mAFB, the sensitivity and specificity of mycobacterial IHC was calculated relative to each (Table 1). The sensitivityand specificity of AFB relative to the composite case definition was $33.3 \%$ and $89.4 \%$ while that of mAFB was $72.2 \%$ and $92.3 \%$. 


\begin{tabular}{|c|c|c|c|}
\hline & & Sensitivity & Specificity \\
\hline & (n) & $\%(95 \% \mathrm{Cl})$ & $\%(95 \% \mathrm{Cl})$ \\
\hline $\begin{array}{l}\text { mycobacterial IHC vs. } \\
\text { AFB }\end{array}$ & (71) & $69.2(38.6-91.0)$ & 89.7 (79.0-96.1) \\
\hline $\begin{array}{l}\text { mycobacterial IHC vs } \\
\text { mAFB }\end{array}$ & (44) & $43.8(19.7-70.1)$ & $89.2(71.8-97.7)$ \\
\hline $\begin{array}{l}\text { mycobacterial IHC vs } \\
\text { culture }\end{array}$ & (51) & $45.8(25.6-67.2)$ & $77.8(57.7-91.4)$ \\
\hline $\begin{array}{l}\text { mycobacterial IHC vs } \\
\text { composite positivity }\end{array}$ & (79) & $45.7(28.8-63.3)$ & 97.7 (88.0-99.9) \\
\hline $\begin{array}{l}\text { AFB vs composite } \\
\text { positivity }\end{array}$ & (71) & $33.3(15.6-55.3)$ & $89.4(77.0-96.5)$ \\
\hline $\begin{array}{l}\text { mAFB vs composite } \\
\text { positivity }\end{array}$ & (44) & $72.2(46.5-90.3)$ & $92.3(74.8-99.0)$ \\
\hline \multicolumn{4}{|c|}{$\begin{array}{l}\text { The sensitivity and specificity of mycobacterial IHC was calculated in comparison to histochemical } \\
\text { staining, culture and a composite reference standard in which demonstration of organisms by any } \\
\text { combination of these other techniqes was considered positive. Histochemical stains were also evaluated } \\
\text { in comparison to the reference standard. IHC, Immunohistochemistry; AFB, acid-fast bacilli; mAFB, } \\
\text { modified acid-fast bacill; n, number; } \mathrm{Cl} \text {, confidence interval. }\end{array}$} \\
\hline
\end{tabular}

Conclusions: We found mycobacterial IHC to be well adopted by non-infectious disease trained anatomic pathologists with increased specificity relative to both AFB and mAFB. The sensitivity of this new assay was higher than that of AFB, but lower than mAFB. These results support the use of $\mathrm{IHC}$ as an adjunctive tool in the diagnosis of mycobacterial infections in routine practice, and suggest its potential role in the adjudication of equivocal histochemical staining or as a more rapid screening test.

\section{Scedosporium spp. Infections in Immunocompromised Patients: A Case Series}

Mia DeSimone ${ }^{1}$, Jessica Crothers ${ }^{1}$, Isaac Solomon ${ }^{1}$, Alvaro Laga ${ }^{1}$

${ }^{1}$ Brigham and Women's Hospital, Boston, MA

Disclosures: Mia DeSimone: None; Jessica Crothers: None; Isaac Solomon: None; Alvaro Laga: None

Background: Opportunistic infections with rare pathogens are increasingly recognized in immunocompromised individuals. Scedosporium can cause asymptomatic colonization, cutaneous lesions, and disseminated disease. To further characterize the clinicohistopathological spectrum of scedosporiosis, we conducted a retrospective 20 -year study.

Design: Microbiology laboratory results at a large academic medical center were reviewed, and 32 patients with at least one culture positive for Scedosporium/Pseudallescheria spp. were identified from 1998-2018. Concurrent surgical pathology specimens were obtained in 16 patients and were included in this study. Patient demographics, clinical presentation, treatment, and outcomes were collected from electronic medical records.

Results: All 16 patients (mean age 56 years; $56 \%$ female) were immunocompromised: 10 transplant recipients, 3 with cystic fibrosis, 3 with autoimmune disorders. Presentation varied from skin/soft tissue infections $(n=5)$ to pneumonia $(n=4) ; 7$ patients were determined to be asymptomatically colonized. Concurrent cultures identified $S$. apiospermum/P. bodyii in 14 patients and $S$. prolificans in two patients. Serum $(1,3)$ beta-D-glucan was elevated in $4 / 9(44 \%)$ patients, while galactomannan was negative in $11 / 12$ (92\%). Fungal elements were identified histologically in 8 patients. Periodic Acid-Schiff and methenamine silver stains highlighted branched septate hyphae and conidia, indistinguishable from other hyaline mold species, including Aspergillus and Fusarium. Granulomatous and/or suppurative inflammation, necrosis, and angioinvasion were variably present. Management included surgical debridement, antifungal therapy, and reduction of immunosuppression. Two of the 5 patients with skin/soft tissue infections resolved with treatment, while the remaining 3 , including both cases of S. prolificans, developed disseminated disease and died.

Conclusions: Accurate and timely diagnosis of Scedosporium infection in immunocompromised patients is vital to ensure adequate clinical management, especially given the genus' enhanced virulence and drug resistance profile. As clinical presentation, histologic inflammatory pattern, and fungal morphology overlap with other opportunistic fungal infections, correlation with cultures and/or molecular data is critical for diagnosis. Our study, although limited, highlights the rarity of scedosporiosis and suggests that skin/soft tissue infections portend a worse prognosis and that S. prolificans is a more virulent species. 


\section{Acute Invasive Fungal Sinusitis: Early detection by Frozen Section Analysis}

Preethi Dileep Menon ${ }^{1}$, Rahaf Alkhateb ${ }^{1}$, Daniel Mais ${ }^{1}$

${ }^{1}$ The University of Texas Health Science Center at San Antonio, San Antonio, TX

Disclosures: Preethi Dileep Menon: None; Rahaf Alkhateb: None; Daniel Mais: None

Background: Acute invasive fungal sinusitis (AIFS) is an aggressive form of fungal sinusitis in which early diagnosis and intervention are known to improve patient outcome. Intraoperative consultation with frozen section has been shown to decrease time to diagnosis when compared with permanent section pathology. This study is intended to determine diagnostic accuracy of frozen section in AlFS at a single institution.

Design: The University Hospital database was accessed to find archived cases in which frozen section was performed for evaluation for AIFS between the years 2009-2018. Frozen sections were considered positive for AIFS if invasive hyphal forms were reported with the exception of candida. All cases were reviewed by an experienced pathologist. The frozen section findings were compared with the permanent sections, including tissue microbial stains, as well as tissue culture. The sensitivity, specificity, positive predictive value (PPV), and negative predictive value (NPV) were estimated with $95 \%$ confidence interval.

Results: Twenty seven (27) patients with a total of sixty seven (67) frozen section evaluations for AIFS were included in the study. Thirtyfive of the biopsy specimens (35/67 or $52.2 \%$ ) were considered positive for AIFS on final pathology, while the remaining $32 / 67$ (47.7\%) were negative. Of the 35 positive biopsy specimens, 31 were positive on frozen section. Of the 32 negative biopsy specimens, all were negative for fungal organisms on frozen section. Frozen section diagnosis demonstrated a sensitivity of $88.6 \%(95 \% \mathrm{Cl}, 0.72-0.96)$, specificity of $100 \%(95 \% \mathrm{Cl}, 0.87-1)$, PPV of $100 \%(95 \% \mathrm{Cl}, 0.86-1)$, and NPV of $88.9 \%(95 \% \mathrm{Cl}, 0.73-0.96)$.

Conclusions: This study represents the largest series assessing the diagnostic accuracy of frozen section analysis in AIFS. The results confirm the value of intraoperative consultation with frozen section for confirming AIFS and provide a quantitative estimate of the reliability of negative results.

\section{Histologic Characterization of Gastrointestinal Mucosal Biopsy Samples in Stem Cell Transplant Recipients on Adenovirus Therapy}

Sarah Elsoukkary ${ }^{1}$, Rosemary Soave ${ }^{1}$, Melanie Johncilla², Meredith Pittman ${ }^{1}$

${ }^{1}$ New York-Presbyterian/Weill Cornell Medical Center, New York, NY, ${ }^{2}$ New York-Presbyterian Hospital/Weill Cornell Medical Center, New York, NY

Disclosures: Sarah Elsoukkary: None; Rosemary Soave: None; Melanie Johncilla: None; Meredith Pittman: None

Background: Adenovirus causes up to $10 \%$ of viral illness worldwide, including enterocolitis. Immunocompetent individuals experience transient symptoms, but immunocompromised patients, like stem cell transplant recipients, can develop life-threatening disease. Brincidofovir is an acyclic nucleoside phosphonate with activity against adenovirus that may be used in this patient population. Parsing out the cause of gastrointestinal (GI) symptoms in these patients is challenging, and the effect of brincidofovir on the GI tract is unknown. The aim of our study was to investigate the histologic features in the GI tract of patients taking brincidofovir.

Design: Adults status post allogeneic stem cell transplant who had GI biopsy samples obtained before and after receiving brincidofovir were included. Thus far, 5 patients have had histologic slides reviewed. Clinical information, including dates of transplant, adenovirus diagnosis, and brincidofovir treatment were obtained from the medical record. All had adenoviremia by PCR; one also tested positive for both fecal and respiratory infection. Post-therapy GI biopsies were taken within 1-10 days of a patient receiving brincidofovir.

Results: Histology varied amongst patients, but there was minimal variation in a patient's own pre- and post-therapy pathology (Table 1). Only Patient 1 had non-GI graft-versus-host disease (GVHD) in the skin, but her pre- and post-therapy samples contained rare apoptosis insufficient for a diagnosis GI GVHD. Patients 2 and 3 showed increased epithelial cell apoptosis with crypt loss in pre- and post- biopsies. Patient 4 had severe adenovirus enterocolitis with nuclear inclusions, abundant epithelial cell apoptosis, crypt loss and neutrophilic inflammation; his post-treatment biopsies showed further crypt loss. Patient 5 had the only discrepant biopsies, with focal active colitis prior to treatment, but increased epithelial cell apoptosis in post-treatment samples. Both patients with intestinal adenovirus involvement had histologic changes reminiscent of GVHD (Figures 1,2). 


\section{ABSTRACTS | INFECTIOUS DISEASE PATHOLOGY}

Table 1. Clinicopathologic Features in Stem-Cell Patients Receiving Brincidofovir

\begin{tabular}{|c|c|c|c|c|c|c|c|}
\hline Patient & Age & Sex & $\begin{array}{l}\text { Adenovirus } \\
\text { Diagnosis } \\
\end{array}$ & $\begin{array}{l}\text { Pre-Brincidofovir } \\
\text { Symptoms }\end{array}$ & $\begin{array}{l}\text { Pre-Brincidofovir } \\
\text { Histology }\end{array}$ & $\begin{array}{l}\text { Post-Brincidofovir } \\
\text { Symptoms }\end{array}$ & $\begin{array}{l}\text { Post-Brincidofovir } \\
\text { Histology }\end{array}$ \\
\hline 1 & 67 & $\mathrm{~F}$ & $\begin{array}{l}\text { Plasma, } \\
\text { Respiratory by } \\
\text { PCR }\end{array}$ & $\begin{array}{l}\text { Nausea, } \\
\text { Vomiting }\end{array}$ & $\begin{array}{l}\text { Upper GI: } \\
\text { scattered epithelial } \\
\text { apoptotic cells } \\
\text { (<4/tissue } \\
\text { fragment) }\end{array}$ & $\begin{array}{l}\text { Nausea, } \\
\text { Vomiting }\end{array}$ & $\begin{array}{l}\text { Upper GI: } \\
\text { scattered epithelia } \\
\text { apoptotic cells } \\
\text { (<4/tissue } \\
\text { fragment) }\end{array}$ \\
\hline 2 & 68 & $\mathrm{M}$ & Plasma by PCR & $\begin{array}{l}\text { Nausea, } \\
\text { Vomiting, } \\
\text { Diarrhea }\end{array}$ & $\begin{array}{l}\text { Lower Gl: } \\
\text { epithelial apoptotic } \\
\text { cells and } \\
\text { occasional crypt } \\
\text { loss }\end{array}$ & Diarrhea & $\begin{array}{l}\text { Lower Gl: } \\
\text { epithelial apoptotic } \\
\text { cells }\end{array}$ \\
\hline 3 & 37 & $F$ & $\begin{array}{l}\text { Plasma, Fecal by } \\
\text { PCR }\end{array}$ & $\begin{array}{l}\text { Nausea, } \\
\text { Vomiting, } \\
\text { Diarrhea }\end{array}$ & $\begin{array}{l}\text { Lower Gl: } \\
\text { epithelial apoptotic } \\
\text { cells and } \\
\text { occasional crypt } \\
\text { loss; adenovirus } \\
\text { IHC negative }\end{array}$ & $\begin{array}{l}\text { Nausea, } \\
\text { Vomiting, } \\
\text { Diarrhea }\end{array}$ & $\begin{array}{l}\text { Lower GI: } \\
\text { epithelial apoptotic } \\
\text { cells; adenovirus } \\
\text { IHC positive }\end{array}$ \\
\hline 4 & 61 & $\mathrm{~F}$ & $\begin{array}{l}\text { Plasma by PCR; } \\
\text { Intestinal by IHC }\end{array}$ & Diarrhea & $\begin{array}{l}\text { Upper Gl: } \\
\text { abundant epithelial } \\
\text { apoptotic cells, } \\
\text { surface viral } \\
\text { cytopathic effect } \\
\text { Lower GI: } \\
\text { abundant epithelial } \\
\text { apoptotic cells, } \\
\text { crypt drop- } \\
\text { out, lamina } \\
\text { propria } \\
\text { neutrophils, and } \\
\text { surface viral } \\
\text { cytopathic effect }\end{array}$ & Diarrhea & $\begin{array}{l}\text { Lower Gl: } \\
\text { confluent crypt } \\
\text { loss and abundant } \\
\text { epithelial apoptotic } \\
\text { cells; } \\
\text { negative viral } \\
\text { cytopathic effect } \\
\text { and adenovirus } \\
\text { IHC }\end{array}$ \\
\hline 5 & 63 & $\mathrm{~F}$ & Plasma by PCR & Diarrhea & $\begin{array}{l}\text { Lower GI: } \\
\text { Focal active colitis }\end{array}$ & Diarrhea & $\begin{array}{l}\text { Lower Gl: } \\
\text { epithelial apoptotic } \\
\text { cells and } \\
\text { occasional crypt } \\
\text { los }\end{array}$ \\
\hline
\end{tabular}

Figure 1 - 1444

Figure 1. Adenovirus Enterocolitis, $\mathrm{H} \& \mathrm{E}$

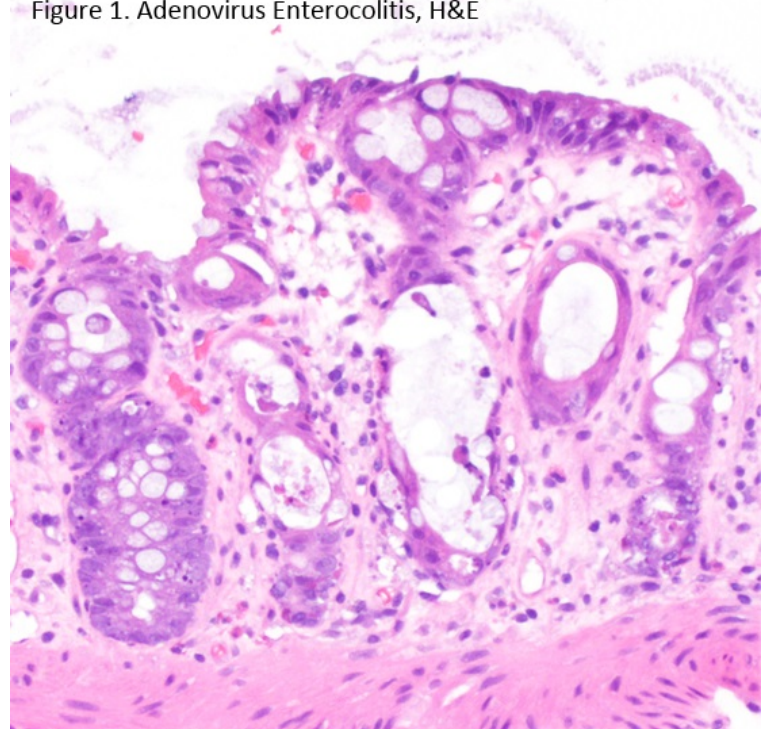

Figure 2 - 1444

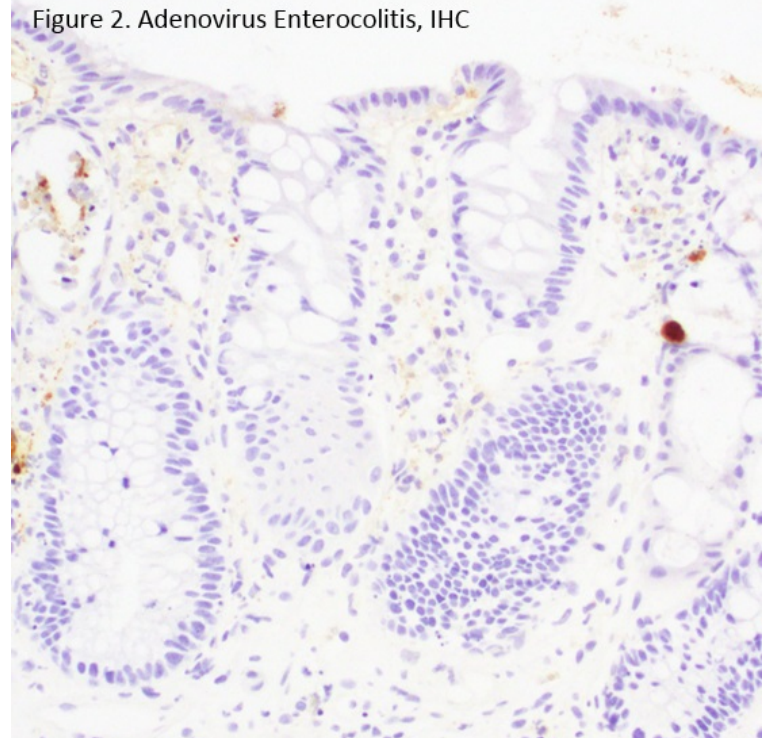

Conclusions: Adenovirus enterocolitis and gastrointestinal GVHD have overlapping features, including epithelial cell apoptosis and crypt drop-out. Although our sample size thus far is small, the absence of characteristic histologic findings across patient samples after brincidofovir therapy may indicate a lack of significant GI toxicity with this medication, and further study is required. 


\section{Impact of a Rapid PCR Molecular Respiratory Panel in the Outpatient Pediatric Clinical Setting}

Maira Gaffar ${ }^{1}$, Jennifer Reppucci ${ }^{1}$, Maria Kelly ${ }^{1}$, Molly Posa ${ }^{1}$, Kenneth Rand ${ }^{1}$, Stacy Beal ${ }^{1}$

${ }^{1}$ University of Florida, Gainesville, FL

Disclosures: Maira Gaffar: None; Jennifer Reppucci: None; Maria Kelly: None; Molly Posa: None; Kenneth Rand: None; Stacy Beal: Grant or Research Support, FilmArray

Background: In 2016, the FDA approved the FilmArray Respiratory Panel EZ (EZ), a CLIA-waived PCR assay which tests for 14 common respiratory pathogens. The assay requires minimal hands-on time and takes approximately 1 hour to complete. While lab-based PCR assays have shown benefits in hospital and emergency department (ED) settings, they are rarely used in outpatient practice due to the turn-around time and cost. More commonly, rapid antigen tests (Ag) for influenza and respiratory syncytial virus (RSV) are performed, which have limited sensitivity. Our study investigated the effectiveness of the EZ performed in real-time in a pediatric setting with regards to accurate pathogen identification and clinical efficiency.

Design: This study was conducted at 2 outpatient pediatric clinics from January to March 2018. The study population were pediatric patients at the outpatient pediatric clinics with acute respiratory symptoms. Clinic $A(A)$ utilized $E Z$ in real-time. Clinic $B(B)$ used point of care Ag testing only but the remaining samples were frozen and tested within 30 days using EZ. An electronic chart review was conducted to identify patient demographics, appointment duration and pathogen identification.

Results: There were 203 encounters across both sites $(A=107 ; B=96)$. Most patients were $<4(A=69 ; B=49)$ or $5-17$ years of age $(A=37$; $B=44)$. There were similar numbers of female $(F)$ and male $(M)$ patients $(A: F=53, M=54 ; B$ : $F=44, M=43)$. Appointment duration varied by location and testing performed $(A: E Z(83)=49.2$ minutes $(\min ), E Z+A g(17)=54.1 \mathrm{~min} ; \mathrm{B}: \mathrm{Ag}(92)=61$ min. $A$ total of 212 pathogens were identified $(A=112 ; B=100)$ including $10(A=6 ; B=4)$ dual/triple infections. $A$ total of $110(A=17 ; B=93)$ samples had both $E Z$ and $A g$. Results matched in 64 samples (58\%). The EZ found an organism not tested by Ag in 43 samples (39\%). Ag+/EZ- was identified in 2 samples $(1.8 \%)$ and one sample $(0.9 \%)$ tested $\mathrm{Ag}-/ \mathrm{EZ}+$.

\begin{tabular}{|l|l|l|}
\hline Respiratory Pathogen & Clinic A & Clinic B \\
\hline Adenovirus & 5 & 6 \\
\hline Chlamydophilia pneumonia & 1 & 0 \\
\hline Coronavirus & 12 & 8 \\
\hline Human Metapneumovirus & 5 & 12 \\
\hline Influenza A & 8 & 24 \\
\hline Influenza B & 3 & 4 \\
\hline Parainfluenza & 1 & 1 \\
\hline Respiratory Syncytial Virus & 3 & 10 \\
\hline Rhinovirus & 14 & 21 \\
\hline Negative PCR assay & 42 & 32 \\
\hline
\end{tabular}

Conclusions: Although molecular diagnostic tests for respiratory pathogens are limited in outpatient use, we demonstrated that EZ was more accurate in pathogen identification, decreased appointment duration and allowed for targeted anticipatory guidance. While the cost of this test is more than traditional antigen testing, overall healthcare costs may be lower. Future investigations could be conducted to determine if their usage would also decrease unnecessary antibiotics, radiologic imaging, invasive testing and ED visits.

\section{Routine Microorganism Stains Provide Little Value in the Evaluation of Lymph Node Biopsies for Bacterial Infection: Implications for Test Utilization}

Christopher Hergott ${ }^{1}$, Alvaro Laga ${ }^{1}$, Olga Weinberg ${ }^{2}$, Isaac Solomon ${ }^{1}$

${ }^{1}$ Brigham and Women's Hospital, Boston, MA, ${ }^{2}$ Children's Hospital Boston, Boston, MA

Disclosures: Christopher Hergott: None; Alvaro Laga: None; Olga Weinberg: None; Isaac Solomon: None

Background: Evaluation of lymph node biopsies for infectious disease remains an ongoing challenge for hematopathologists, particularly in the absence of concurrent culture data. Histochemical stains are utilized frequently to visualize microorganisms in biopsy tissue, especially when reactive histology or congruent clinical findings raise suspicion for infection. Despite their widespread use, evaluations of the diagnostic utility of microorganism stains for lymph nodes remain anecdotal and largely unexplored, particularly for bacterial infections. Here, we leverage 10 years of lymph node biopsy pathology and clinical data to systematically evaluate results from the three most commonly ordered pathogen stains: the Gram stain, acid-fast bacilli (AFB), and the methenamine silver stain (MSS), and identify their impact on diagnoses.

Design: Using institutional databases, we analyzed 313 microorganism stains performed on 178 lymph node biopsies received between 9/1/2008 and 9/1/2018 and accessioned to hematopathology, including 123 Gram stains, 154 AFB stains, and 36 MSS stains. We 
correlated stain results with histologic findings, pathologic diagnosis, and tissue culture results when performed. Manual chart review was undertaken for any case with a positive stain, positive culture, or histology suggestive of inflammation or any reactive changes.

Results: Strikingly, only 1 of the 123 collected Gram stains yielded visible bacteria ( $0.8 \%)$. This specimen yielded no culture growth and the patient was treated empirically with antibiotics. Among specimens displaying inflammatory or other reactive changes (92/123; 74.8\%), Gram stains were universally negative. Bacterial culture data was available for only 31 of the 92 reactive specimens (33.7\%) and yielded no pathogen growth. In contrast, 9 of the 154 AFB stains (5.8\%) identified mycobacteria and corresponded with growth in all cultured cases $(8 / 8 ; 100 \%)$. Among MSS stains, 1 of $36(2.8 \%)$ displayed visible fungi and yielded a positive culture for Histoplasma capsulatum.

Conclusions: Systematic analysis of lymph node biopsies collected over a decade reveals marked differences in agreement rates between routine microbial stains and associated histologic and clinical data. While positive stains for mycobacteria and fungi were often confirmed by positive culture and clinical follow-up, Gram stains yielded no actionable information for any patient in the study period. More judicious use of this stain may be warranted in lymph node evaluation in the future.

\section{Human Immunodeficiency Virus-Associated Lymphadenopathy and Lymphoproliferations: The Range of Pathologic Diagnoses in the Time of Highly-Active Anti-Retroviral Therapy (HAART)}

David Kim¹, Daniel Mais ${ }^{1}$, Lianqun Qiuํ, Alia Nazarullah ${ }^{1}$, Edward Medina ${ }^{1}$

${ }^{1}$ The University of Texas Health Science Center at San Antonio, San Antonio, TX

Disclosures: David Kim: None; Daniel Mais: None; Lianqun Qiu: None; Alia Nazarullah: None; Edward Medina: None

Background: The spectrum of pathologic findings in Human Immunodeficiency Virus (HIV) - associated lymphadenopathy was described decades ago, at a time when the course of infection was progressive and relatively short. The spectrum of lymphoproliferations in HIVinfected patients has changed since the introduction of highly active anti-retroviral therapy (HAART), with very few studies on trends. The aim of this study was to report the spectrum of diagnoses found upon examination of lymph nodes and lymphoproliferations over the past 10 years in HIV-positive patients at a single tertiary care hospital.

Design: We retrospectively reviewed all lymph nodes and lymphoproliferations in patients infected with HIV between 2009 and 2018 . The pathologic findings were recorded, with hematolymphoid neoplasms classified according to the WHO 2016 classification. Medical records were reviewed. Finally, the diagnoses were correlated with HAART therapy compliance and CD4 counts at the time of diagnosis.

Results: In a total of 147 biopsies with HIV related lymphoproliferations from 120 patients, the diagnoses included benign/non-infectious (23\%), benign/infectious (17\%), Kaposi sarcoma/Castleman disease (KS/CD) $(18 \%)$, lymphoma $(34 \%)$ and carcinoma $(7.5 \%)$. Infectious etiologies included syphilis (28\%), Mycobacterium avium complex (MAC, $20 \%$ ), Histoplasma (12\%), tuberculosis (12\%), and others. The lymphomas included Hodgkin lymphoma (32\%), DLBCL (24\%), Burkitt lymphoma (17\%), PBL (15\%), PEL (9.8\%), and ALCL (2.4\%). EBV was positive in $68.4 \%$ of lymphomas and HHV8 was positive in $23.5 \%$ of lymphomas. $27 \%$ of the lymphomas showed bone marrow involvement. Comparing the etiologies to demographic and clinical variables, non-infectious reactive lymphadenopathy and KS/CD appear to involve relatively younger patients than malignancies $(p<0.05)$. Malignancies including lymphoma were more frequent in patients compliant with HAART therapy $(63 \%, p<0.001)$, with slightly higher CD4 counts. See Table 1 for summary. 
Figure $1-1447$

Table 1 Summary of Pathologic Diagnoses with Clinical and Demographic Variables

\begin{tabular}{|c|c|c|c|c|c|c|c|}
\hline Diagnosis & $\mathrm{N}$ & Age & CD4 Count & Viral Load & $\begin{array}{l}\text { Lymphadenopathy* } \\
\text { (Localized/ } \\
\text { Generalized) }\end{array}$ & $\begin{array}{l}\text { HAART } \\
\text { Therapy* }\end{array}$ & $\begin{array}{c}\text { Compliance } \\
\text { Rate }^{* \star \star x}\end{array}$ \\
\hline $\begin{array}{l}\text { Benign } \\
\text {-non-infectious }\end{array}$ & 28 & $\begin{array}{c}37.6 \pm 2.2 \\
(18-65)\end{array}$ & $\begin{array}{c}359.2 \pm 63.3 \\
(40-1140)\end{array}$ & $\begin{array}{c}650933 \\
\left(0-8.6 \times 10^{\circ}\right) \\
\end{array}$ & $22 / 6$ & $18(64.3 \%)$ & $7(25.0 \%)$ \\
\hline $\begin{array}{l}\text { Benign } \\
\text {-infectious }\end{array}$ & 20 & $\begin{array}{c}37.1 \pm 2.2 \\
(24-56)\end{array}$ & $\begin{array}{c}103.5 \pm 29.3 \\
(0-486)\end{array}$ & $\begin{array}{c}375312 \\
\left(0-2.43 \times 10^{6}\right)\end{array}$ & $14 / 6$ & $14(70 \%)$ & $7(35.0 \%)$ \\
\hline $\begin{array}{l}\text { Kaposi Sarcoma/ } \\
\text { Castleman disease }\end{array}$ & 22 & $\begin{array}{c}34.9 \pm 2.3 \\
(20-55)\end{array}$ & $\begin{array}{c}123.6 \pm 26.6^{\mathrm{a}} \\
(12-445)\end{array}$ & $\begin{array}{c}126939 \\
\left(29-5.67 \times 10^{5}\right)\end{array}$ & $10 / 12$ & $13(59.1 \%)$ & $4(18.2 \%)$ \\
\hline Lymphoma & 41 & $\begin{array}{c}43.5 \pm 1.9 \\
(22-60)\end{array}$ & $\begin{array}{c}260.1 \pm 35.6 \\
(35-834)\end{array}$ & $\begin{array}{c}286548 \\
\left(0-7.6 \times 10^{\theta}\right)\end{array}$ & $20 / 21$ & $35(85.4 \%)$ & $23(56.1 \%)$ \\
\hline Burchett & 7 & $\begin{array}{c}35.6 \pm 5.1 \\
(22-60)\end{array}$ & $276.6 \pm 61.9$ & 21631 & $5 / 2$ & $5(71.4 \%)$ & $4(57.1 \%)$ \\
\hline - DLBCL & 10 & $\begin{array}{l}52 \pm 4.3 \\
(29-74)\end{array}$ & $272 \pm 87.5$ & 9934 & $1 / 9$ & $10(100 \%)$ & $8(80 \%)$ \\
\hline PEL & 4 & $\begin{array}{l}43.3 \pm 5.6 \\
(33-59)\end{array}$ & $271 \pm 163$ & 823765 & $3 / 1$ & $3(75 \%)$ & $2(50 \%)$ \\
\hline PBL & 6 & $\begin{array}{l}40.2 \pm 4.2 \\
(30-57)\end{array}$ & $112.5 \pm 26.2$ & 1317102 & $3 / 3$ & $3(50 \%)$ & $2(33.3 \%)$ \\
\hline Hodgkin & 13 & $\begin{array}{l}42.6 \pm 2.8 \\
(31-58)\end{array}$ & $322 \pm 65.3$ & 22938 & $8 / 5$ & $13(100 \%)$ & $6(46.2 \%)$ \\
\hline ALCL & 1 & 48.00 & 64 & 1870 & $0 / 1$ & $1(100 \%)$ & $1(100 \%)$ \\
\hline Carcinoma & 9 & $\begin{array}{c}52.9 \pm 2.8^{*} \\
(32-60)\end{array}$ & $\begin{array}{c}319.8 \pm 56.2 \\
(117-658)\end{array}$ & $\begin{array}{c}1834^{\mathrm{b}} \\
(0-11229)\end{array}$ & $7 / 2$ & $9(100 \%)$ & $8(88.9 \%)$ \\
\hline Total & 120 & $40.4 \pm 1.1$ & $\begin{array}{c}237.6 \pm 22.3 \\
(0-1140)\end{array}$ & $\begin{array}{c}333007 \\
\left(0-8.6 \times 10^{6}\right)\end{array}$ & $73 / 47$ & $89(74.2 \%)$ & $49(40.8 \%)$ \\
\hline
\end{tabular}

Results were expressed as mean \pm SEM (range) for age, CD4 count and HIV viral load; and case numbers (percentage of the disease) for HAART therapy and compliance rate; $* P<0.05$, and ${ }^{* * *} P<$ 0.001 determined by Fisher exact test, ${ }^{*} P<0.05$ vs other groups, ${ }^{a} P<0.05$, vs benign-noninfectious an lymphoma groups, $P$ P $<0.05$ vs Kaposi Sarcoma/Castleman disease, determined by one-way ANOVA primary

Conclusions: In this era of HAART therapy, HIV related lymphomas are on the rise, and seen more commonly in patients with therapy compliance and higher CD4 counts. Larger series may be needed to identify variables to clinically predict etiologies of HIV related lymphadenopathy.

\section{Significant Impact of Highly Active Antiretroviral Therapy (HAART) on Morphologic Progression of High-Risk HPV Anal Squamous Dysplasia in HIV-infected Patients}

Katrina Krogh ${ }^{1}$, Audrey Deeken-Draisey², Ryan Jones ${ }^{1}$, Leyu Sun ${ }^{1}$, Jie Liao ${ }^{1}$, M. Sambasiva Rao ${ }^{1}$, Guang-Yu Yang ${ }^{1}$

${ }^{1}$ Northwestern University, Chicago, IL, ${ }^{2}$ Northwestern Memorial Hospital, Chicago, IL

Disclosures: Katrina Krogh: None; Audrey Deeken-Draisey: None; Ryan Jones: None; Leyu Sun: None; Jie Liao: None; M. Sambasiva Rao: None; Guang-Yu Yang: None

Background: Higher prevalence of anal HPV in HIV+ patients compared to HIV- patients has been observed. Although highly active antiretroviral therapy (HAART) is effective in controlling HIV, its impact on HPV-induced anal dysplasia is unclear. In this study, we analyzed the impact of HAART on morphologic progression of HPV-induced anal dysplasia using patient specimens before and after their HAART initiation. We performed an extensive case-controlled clinicopathologic and immunohistochemical (IHC) study using our large cohort of patients pre- and post-HAART.

Design: Twenty HIV+ patients with dysplastic anal biopsies collected both prior to HAART initiation ("pre-HAART") and during HAART ("post-HAART") were included. Tissue was graded from anal intraepithelial neoplasia-1 (AIN-1)-AIN-3. Pre-HAART, grade change was measured from a presumed previous grade of 0; post-HAART, grade change was calculated between pre- and post-HAART biopsies. Concurrent viral loads (VL) and CD4 counts were obtained. IHC of Waf1p21 and Ki-67 was performed, scored, and compared pre- and post-HAART. Lymphocytic reaction was also scored: focal minimal=1, focal enhanced=2, lichenoid=3, and intraepithelial=4.

Results: Patient age pre-HAART ranged from 22-57 (median 42 years) and all were male. Pre-HAART, average HIV duration was 11.1 (0.5-27.9 years), VL was 36,724 (36-208,087 copies/mL), and CD4 count was 234 (8-601 cells/mm³). At post-HAART biopsy, average duration on HAART was 2.4 (0.2-8.4 years), VL was 78 (0-819 copies/mL), and CD4 count was 394 (36-1015 cells/mm³). Histologic analysis demonstrated that average change in lesion grade while on HAART $(0.35 \pm 0.28)$ was statistically significantly smaller than average change while not on HAART $(1.7 \pm 0.19, P=0.004)$. Linear regression analysis showed that as years without HAART increased, lesion grade also increased $\left(P=0.05 ; \mathrm{R}^{2}=0.2\right)$; concurrently, as years on HAART increased, lesion grade decreased $\left(P=0.03 ; \mathrm{R}^{2}=0.23\right)$. Histologically, $75 \%$ (9/12) showed a statistically significant increase in lymphocytic reaction on HAART, with $8 \%(1 / 12)$ showing no change and $17 \%$ $(2 / 12)$ decreasing $(P=0.03)$. Cell cycle/quiescence analysis with Waf1p21 and Ki-67 biomarkers showed no significant changes.

Conclusions: HAART has a significant impact on the progression of anal dysplasia, and patients on HAART show smaller grade increases and slower progression. Our mechanistical study suggests this effect may be due to increased CD4 counts and effective immunosurveillance of pre-invasive neoplastic lesions. 


\section{Questionings About HPV Vaccination}

Katia Leite ${ }^{1}$, Ruan Pimenta², Juliana Canavez ${ }^{2}$, Flavio Canavez², Fernando Souza ${ }^{2}$, Rozany Dufloth², Carmen Estivallet ${ }^{2}$, L.H. Camara-Lopes ${ }^{3}$

${ }^{1}$ University of Sao Paulo Medical School, São Paulo, SP, Brazil, ${ }^{2}$ Genoa/LPCM Laboratory, São Paulo, SP, Brazil, ${ }^{3}$ São Paulo, SP, Brazil

Disclosures: Katia Leite: None

Background: Nearly 500,000 new cases of cervix cancer (CC) are estimated annually worldwide, $80 \%$ occuring in middle and low income countries. In Brazil the mean incidence of CC is $15.43 / 100,000$, but reaches $46 / 100,000$ in some regions. For $2018,16,370$ new cases are expected, being registered 5,430 deaths in 2013. CC are almost entirely attributable to human papillomavirus (HPV) infection. There are three vaccines currently licensed to prevent pre-invasive and invasive cancer of cervix, vulva and vagina: Gardasil(4vHPV; Merck), Cervarix(2vHPV; GlaxoSmithKline) and the new 9-valent Gardasil 9 (9vHPV, Merck). They are intended to induce immunogenicity against HPV6, 11,16, 18 (Gardasil 4vHPV), HPV16 and 18 (Cervarix 2vHPV) and HPV 6, 11, 16, 18, 31, 33, 45, 52 and 58 (Gardasil 9vHPV). The success of vaccination depends on the vaccine coverage, the number of doses per patient, cross protection provided against HPV, but mainly on the prevalence of HPV genotypes in different populations.

Our aim is to search for HPV infection in cervical samples, describing the type-specific HPV in Brazilian women from a high-income southeast region which have access to the private health system.

Design: From January $1^{\text {st }} 2015$ to August $31^{\text {st }} 2018,21,017$ liquid-based (LBC) cervical specimens were received for cytology and HPV detection. Before the cytology slides performance, an 1,000 $\mu$ l aliquot were taken from the LBC fixative and submitted to automated DNA extraction using QIAsymphony DSP DNA Mini Kit. Multiplex PCR followed by capillary electrophoresis was used for HPV detection and classification.

Results: The mean age of patients was 36.4 years-old. It was 32.3 yo for HPV positive and 37.1 yo for negative cases. HPV was detected in $895(4.3 \%)$ of the cases. All genotypes and their prevalence are exposed in graphic 1 . There were 73 cases with multiple HPV-type infection ( $8.1 \%$ of the HPV positive cases), being the majority association of high-risk HPV. From these cases, $47.9 \%$ were diagnosed HSIL or LSIL in cytology. Low-risk and high-risk association was identified in $16.4 \%$ of cases.

Figure $1-1449$

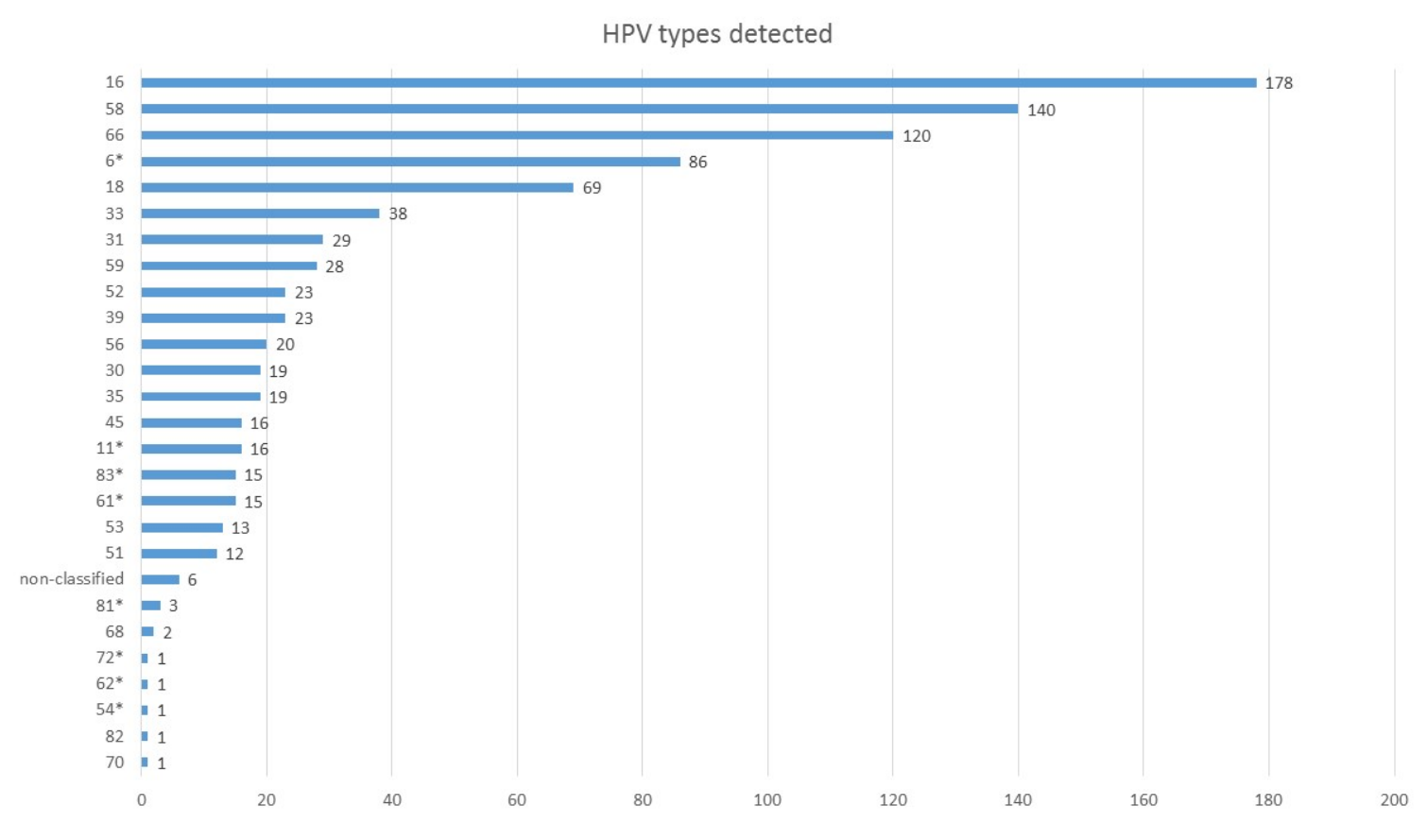

Conclusions: In a private laboratory in the southeast region of Brazil from a total of $895 \mathrm{HPV}$ positive cases, 258(28.8\%) were representative of high or possible-high risk $\operatorname{HPV}[66,59,39,56,30,35,53,51,68,82,70]$ not contemplated by the available vaccines, even the 9vHPV. The government and the health system should be aware of the possibility to not being immunizing a considerable percentage of women that will need to maintain the cervical 


\section{ABSTRACTS | INFECTIOUS DISEASE PATHOLOGY}

\section{A Novel RNA In Situ Hybridization Method for the Detection of Mycobacteria in Clinical FFPE Samples}

Na Li ${ }^{1}$, Zhifu Zhang ${ }^{1}$, Li-Chong Wang ${ }^{1}$, Wei Wei ${ }^{1}$, Courtney Anderson ${ }^{1}$, Robert Monroe ${ }^{1}$, Xiao-Jun Ma ${ }^{1}$

${ }^{1}$ Advanced Cell Diagnostics, Newark, CA

Disclosures: Courtney Anderson: Employee, Advanced Cell Diagnostics, Inc; Robert Monroe: Employee, Bio-Techne; Xiao-Jun Ma: None

Background: Acid fast staining (AFS) for the detection of mycobacteria and other acid-fast organisms provides a rapid way of identifying pathogenic organisms in FFPE tissue in contrast to culture methods, which require weeks to perform. While rapid and straightforward, there are several issues with AFS. First, AFS can be challenging and time-consuming to interpret. Second, standard tissue fixatives and processing alters the lipid-rich cell wall of acid-fast organisms which reduces the detection sensitivity in FFPE samples. Last, AFS does not allow for discrimination between various acid-fast organisms, such as mycobacteria tuberculosis (MTB) vs. non-tuberculous mycobacteria (NTM). To address these issues with AFS, we have developed a highly sensitive and specific RNA in situ hybridization (RISH) assay using the RNAscope technology for the detection of mycobacteria rRNA in FFPE tissues and distinction of MTB and NTM.

Design: FFPE serial sections from 50 clinically diagnosed TB patients were collected from five hospitals in China. Samples were tested with AFS or using the RNAscope probes B-MTB-23s-rRNA-1-C1 and B-MTB-NTM-16srRNA-O1 targeting MTB only or both MTB and NTM, respectively, using a modified RNAscope protocol (Protocol I). A subset of the RISH positive samples were subsequently examined using an alternative protocol (Protocol II), which eliminates one pretreatment step. AFS and RISH slides were then analyzed for the presence of positively stained organisms.

Results: Of the 50 TB patient samples, 36 showed AFS-positive organisms while 14 were negative. 38/50 exhibited positive RISH signals

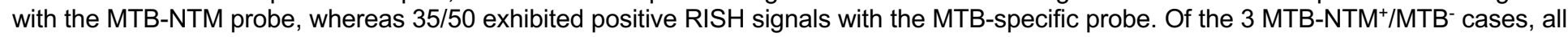
3 were AFS-positive. 28 MTB-NTM+ samples tested using Protocol II yielded the same results. 


\section{ABSTRACTS | INFECTIOUS DISEASE PATHOLOGY}

Table 1. Summary of 50 clinically diagnosed TB samples tested with AFS and RNAscope ISH assays

\begin{tabular}{|c|c|c|c|c|c|}
\hline \multirow[t]{2}{*}{$\begin{array}{l}\text { Sample } \\
\text { number }\end{array}$} & \multirow[t]{2}{*}{$\begin{array}{l}\text { Acid fast staining } \\
\text { (AFS) }\end{array}$} & $\begin{array}{l}\text { RNAscope } 2.5 \text { HD } \\
\text { Red, Protocol I }\end{array}$ & $\begin{array}{l}\text { RNAscope } 2.5 \text { HD } \\
\text { Red, Protocol I }\end{array}$ & $\begin{array}{l}\text { RNAscope } 2.5 \text { HD } \\
\text { Red, Protocol II }\end{array}$ & $\begin{array}{l}\text { RNAscope } 2.5 \text { HD } \\
\text { Red, Protocol II }\end{array}$ \\
\hline & & $\begin{array}{l}\text { B-MTB-NTM- } \\
\text { 16srRNA-O1 }\end{array}$ & $\begin{array}{l}\text { B-MTB-23s-rRNA-1- } \\
\text { C1 }\end{array}$ & $\begin{array}{l}\text { B-MTB-NTM- } \\
\text { 16srRNA-O1 }\end{array}$ & $\begin{array}{l}\text { B-MTB-23s-rRNA-1- } \\
\text { C1 }\end{array}$ \\
\hline 1 & - & - & - & $\mathrm{N} / \mathrm{A}$ & $\mathrm{N} / \mathrm{A}$ \\
\hline 2 & - & - & - & N/A & $\mathrm{N} / \mathrm{A}$ \\
\hline 3 & - & - & - & N/A & N/A \\
\hline 4 & - & + & + & $\mathrm{N} / \mathrm{A}$ & N/A \\
\hline 5 & - & - & - & N/A & $\mathrm{N} / \mathrm{A}$ \\
\hline 6 & + & + & + & + & + \\
\hline 7 & + & + & + & + & + \\
\hline 8 & - & + & + & + & + \\
\hline 9 & - & - & - & $\mathrm{N} / \mathrm{A}$ & $\mathrm{N} / \mathrm{A}$ \\
\hline 10 & + & + & + & + & + \\
\hline 11 & + & + & - & N/A & $\mathrm{N} / \mathrm{A}$ \\
\hline 12 & + & + & + & N/A & $\mathrm{N} / \mathrm{A}$ \\
\hline 13 & + & + & - & N/A & N/A \\
\hline 14 & - & - & - & $\mathrm{N} / \mathrm{A}$ & N/A \\
\hline 15 & - & - & - & N/A & N/A \\
\hline 16 & - & - & - & N/A & N/A \\
\hline 17 & - & - & - & N/A & N/A \\
\hline 18 & - & - & - & N/A & N/A \\
\hline 19 & - & - & - & N/A & N/A \\
\hline 20 & + & + & + & + & + \\
\hline 21 & + & + & + & + & + \\
\hline 22 & + & + & + & + & + \\
\hline 23 & + & + & + & + & + \\
\hline 24 & + & + & + & + & + \\
\hline 25 & + & + & + & + & + \\
\hline 26 & + & + & - & N/A & N/A \\
\hline 27 & + & + & + & + & + \\
\hline 28 & + & + & + & + & + \\
\hline 29 & + & + & + & + & + \\
\hline 30 & + & + & + & + & + \\
\hline 31 & + & + & + & + & + \\
\hline 32 & + & + & + & + & + \\
\hline 33 & + & + & + & + & + \\
\hline 34 & + & + & + & + & + \\
\hline 35 & + & + & + & + & + \\
\hline 36 & + & + & + & + & + \\
\hline 37 & + & + & + & + & + \\
\hline 38 & + & + & + & + & + \\
\hline 39 & - & - & - & N/A & $\mathrm{N} / \mathrm{A}$ \\
\hline 40 & + & + & + & + & + \\
\hline 41 & + & + & + & + & + \\
\hline 42 & + & + & + & + & + \\
\hline 43 & + & + & + & + & + \\
\hline 44 & + & + & + & + & + \\
\hline 45 & + & + & + & N/A & N/A \\
\hline 46 & + & + & + & $\mathrm{N} / \mathrm{A}$ & $\mathrm{N} / \mathrm{A}$ \\
\hline 47 & + & + & + & $\mathrm{N} / \mathrm{A}$ & $\mathrm{N} / \mathrm{A}$ \\
\hline 48 & + & + & + & N/A & N/A \\
\hline 49 & + & + & + & N/A & N/A \\
\hline 50 & + & + & + & + & + \\
\hline
\end{tabular}

Conclusions: We have developed a novel RISH method for the detection of mycobacteria in FFPE tissue. In comparison to AFS, the RISH methodology appears to be more sensitive, detecting 2 additional positive cases. In addition, the RISH method was able to identify 3 cases of probable NTM, a distinction of high clinical relevance owing to the different treatments required for MTB vs. NTM infections. Finally, the $\mathrm{RISH}$ signals were easier to visualize and locate compared to AFS. Overall, our results indicate that the RNAscope assay is a sensitive method to detect mycobacteria in FFPE tissues that allows for differentiation of MTB vs. NTM and is easy to interpret. 


\section{Cross Reactivity in Immunohistochemistry and Serologic Tests for Syphilis in Human Intestinal Spirochetosis: a Pilot Study}

Desiree Lovera Castedo ${ }^{1}$, Pietro Cantú2 ${ }^{\text {, Pillar Venzon }}{ }^{1}$, Daniella Vieira ${ }^{3}$, Ariane Haagsma ${ }^{4}$, Ana Carolina Rodrigues ${ }^{2}$, Ana Paula $^{2}$ Pasinato $^{2}$, Gabriella Di Giunta Funchal' ${ }^{2}$. Flavia Cristina Novaes Gerber ${ }^{2}$, Marlus Gerber ${ }^{2}$, I-Ching Lee ${ }^{1}$

${ }^{1}$ Universidade Federal de Santa Catarina, Florianópolis, SC, Brazil, ${ }^{2}$ Hospital Polydoro Ernani de São Thiago HU/UFSC,

Florianópolis, SC, Brazil, ${ }^{3}$ Hospital Polydoro Ernani de São Thiago HU/UFSC, São Jose, SC, Brazil, ${ }^{4}$ Palhovßa, SC, Brazil

Disclosures: Desiree Lovera Castedo: None; Pietro Cantú: None; Pillar Venzon: None; Daniella Vieira: None; Ariane Haagsma: None; Ana Carolina Rodrigues: None; Ana Paula Pasinato: None; Gabriella Di Giunta Funchal: None; Flavia Cristina Novaes Gerber: None; Marlus Gerber: None; I-Ching Lee: None

\section{Background:}

Human intestinal spirochetosis (HIS) is defined as the colonization of spirochetes attached to the apical cell membrane in the colorectal epithelium. Clinical significance has remained uncertain. The majority of the patients present mild or no clinical complaints, with exception of immunocompromised individuals or invasion of spirochetes beyond the epithelium. The class Spirochaetae has over twenty species; the main etiological agents of HIS are Brachyspira aalborgi and Brachyspira pilosicoli. The etiological agent of Syphillis, Treponema Pallidum (T. pallidum), also belongs to this class. Previous reports highlight the possibility of using immunohistochemistry staining for $T$. pallidum to diagnose HIS. The purpose of our study is to confirm these findings and concomitantly evaluate the possibility of cross reactivity in HIS by Rapid Plasma Reaging test (RPR), a screening test for syphilis, that searches for antibodies found in T. pallidum infection.

Design: Intestinal samples from 11 patients with HIS and no previous history of syphilis infection were retrieved (nine colonoscopic biopsies and two colectomy specimens). Each sample was tested with T. pallidum (Spirochete) polyclonal antibody (Biocare medical)® using immunohistochemical techniques. Blood samples from 5 patients were submitted for Rapid Plasma Reaging test (RPR).

Results: The histological appearance of approximately $2 \mu \mathrm{m}$ thick basophilic fringes is observed on the luminal surface of the large intestinal mucosa. $100 \%$ of the samples were positive for immunohistochemical detection for $T$. pallidum. No positive results were found in the five blood samples tested with RPR.

Figure 1: Colonic epithelium with a thick brush border at the surface of the colonic mucosa, characteristic of Human Intestinal Spirochetosis. Hematoxylin-Eosine. 400x.

Figure 2: Fringes of spirochetes highlighted by immunostainig with T. pallidum antibody. 400x.

Figure 1 - 1451

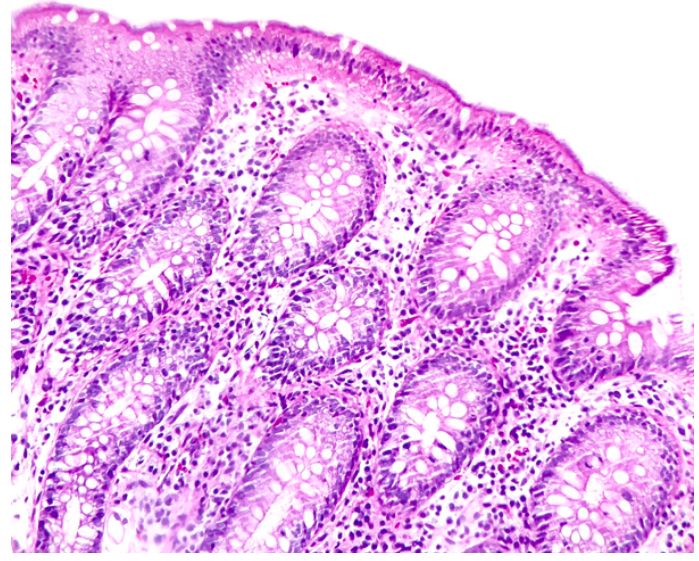

Figure 2 - 1451

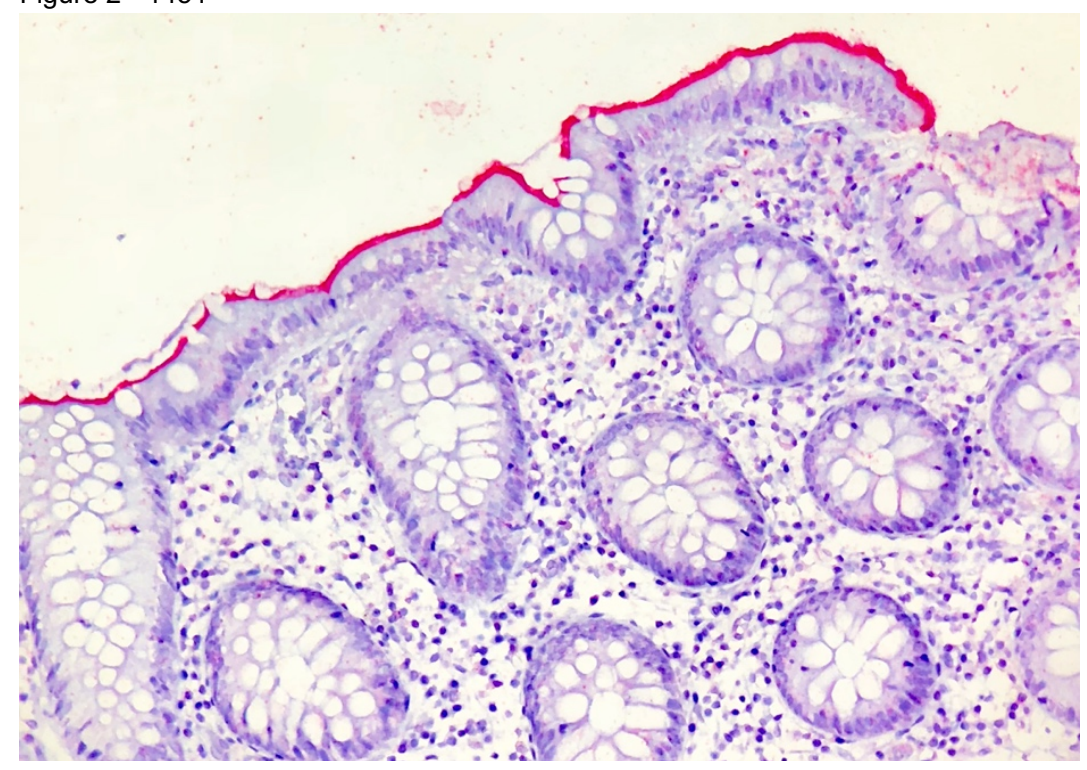

Conclusions: In our cases, we showed that T. pallidum antibody specifically cross-reacts with intestinal spirochetes, and it is useful to confirm the diagnosis of HIS. We also found that there is no cross reactivity between RPR test and intestinal spirochetes infection. Further studies are needed to show if massive spirochetes invasion may affect the serologic results. 


\section{Yield of Microbiologic and Histopathologic AFB studies on Dermatologic Specimens}

Abbye McEwen ${ }^{1}$, Nik Krumm¹, Andrew Bryan ${ }^{1}$

${ }^{1}$ University of Washington, Seattle, WA

Disclosures: Abbye McEwen: None; Nik Krumm: None; Andrew Bryan: None

Background: Dermatologic tissue specimens are unique as the sampled tissue is frequently limited, but additional tissue can be obtained if necessary. In the microbiology laboratory, prioritizing tissue for diagnostic testing is necessary to cover the commonly broad infectious differential for skin biopsies. We hypothesized that in a population with low endemicity for tuberculosis and leprosy, a tiered testing approach could improve initial laboratory stewardship.

Design: Dermatologic patient cases were identified by searching clinical (CP) and anatomic (AP) laboratory information systems from 1/1/2011-12/31/2017. We identified cases with microbiologic data by searching for AFB cultures, non-tuberculous mycobacterial (NTM) PCR, and TB PCR ordered by dermatology clinics or providers. All culture and molecular assays were performed at the University of Washington Clinical Microbiology Laboratory. Histopathologic cases were identified by searching for skin biopsy cases which included the key words AFB, acid-fast, FITE, or mycobacteria in their reports.

Results: A total of 1233 patients were identified, with an overall positivity rate of $1.9 \%$ for AFB studies. The positivity rates for the assays were: $5.4 \%$ (4/74) for molecular, 1.9\% (12/628) for culture, and 1.4\% (11/809) for AFB and/or FITE stains. 239 patients had both AP and CP assays performed, see Table 1. Histopathologic findings for 14 microbiology-confirmed cases included: granuloma (8), abscess (3), Kaposi sarcoma, lymphohistiocytic inflammation, and ulcer/mixed inflammation. Organisms identified were $M$. abscessus (2), $M$. chelonae (4), M. fortuitum (2), M. leprae (2), M. marinum (2), M. massiliense (2), M. paragordonae (1, excluded), M. tuberculosis (3), M. ulcerans (2), and M. marium or M. ulcerans (1).

\begin{tabular}{|l|l|l|}
\hline \multicolumn{2}{|c|}{ Table 1. Dermatologic patient cases with both histologic and microbiologic AFB studies performed. } \\
\hline & $\begin{array}{l}\text { AFB and/or FITE stain } \\
\text { positive }\end{array}$ & $\begin{array}{l}\text { AFB and/or FITE stain } \\
\text { negative }\end{array}$ \\
\hline $\begin{array}{l}\text { AFB culture and/or molecular } \\
\text { postive }\end{array}$ & 4 & 9 \\
\hline $\begin{array}{l}\text { AFB culture and/or molecular } \\
\text { negative }\end{array}$ & 1 & 225 \\
\hline
\end{tabular}

Conclusions: The yield of AFB studies in a region of low endemicity is low for dermatology specimens, but when identified can dramatically impact therapy. Of the 3 TB cases identified, 2 were unexpected, including 1 patient with a negative PPD. NTMs cases were identified and treated, even when granulomas were absent. For cases with both AP and CP studies performed, histopathologic stains beyond H\&E only added value for 1 patient thought to have leprosy. These data suggest the utilization of special stains can be reduced if microbiologic tests are performed unless there is a high clinical suspicion for AFB. The study is limited by the retrospective nature and small number of positive cases where multiple diagnostics were performed.

\section{Hepatitis A in San Diego County: A retrospective review of the 2016-2018 outbreak Tristan McKnight ${ }^{1}$, Mojgan Hosseini ${ }^{2}$ \\ ${ }^{1}$ University of California, San Diego, San Diego, CA, ${ }^{2}$ University of California, San Diego, La Jolla, CA}

Disclosures: Tristan McKnight: None; Mojgan Hosseini: None

Background: The 2016-2018 hepatitis A outbreak in San Diego County (SD) primarily affected non-vaccinated homeless adults with 592 infections, 407 (69\%) hospitalizations and 20 (3.4\%) deaths. Molecular analysis identified a new HAV Ib strain, distinct from other outbreaks. 154 cases (26\%) were treated at the university hospital with liver biopsies performed on 8 cases (5.2\%), providing a unique opportunity to review morphologic features, since liver biopsies for HAV are uncommon. Although the SD outbreak has ended, the CDC continues to monitor similar hepatitis A outbreaks, some connected to the SD outbreak (Arizona, Utah) and others unrelated (Kentucky, Michigan). Involvement of multiple states underscores the importance of this investigation and re-education of pathologists.

Design: Epidemiologic and molecular data were provided by San Diego County Health and Human Services Agency. At the university, a retrospective review was performed of all IgM-positive patients from 2016-2018, including liver biopsies, demographic, laboratory and clinical data.

Results: 592 new lgM positive cases were reported (age range: 5-87, median age 43, 69\% male, $31 \%$ female). 154 patients were treated at the university (age range: $23-100$, median age $46,68 \%$ male, $32 \%$ female). Concurrent $\mathrm{HBV}$ was present in $5.5 \%, \mathrm{HCV}$ in $18.5 \%$, clinically relapsing hepatitis in $10 \%$ and cholestatic hepatitis in $5 \%$. Biopsies included cases with concurrent HBV, HCV, and relapsing acute hepatitis A. Morphological features of severely active hepatitis were identified with confluent and bridging necrosis, lymphoplasmacytic inflammation, canalicular and hepatocytic cholestasis and bile duct injury. 
Conclusions: The outbreak largely affected homeless individuals with and without illicit drug use (34\% and $15 \%)$ and those with a history of drug use only (13\%). $20 \%$ had no risk factors and $13 \%$ lacked history. Mode of transmission was direct person-to-person contact; no common source of food, beverage or drugs was identified. Among male cases, $3.5 \%$ were identified as men who have sex with men (MSM), compared to reported $14-84 \%$ in other outbreaks. A public health emergency was declared and an education/vaccination campaign with distribution of hygiene kits, deployment of bathrooms and hand washing stations was conducted. The outbreak ended on $1 / 23 / 2018$ and now provides an opportunity to re-familiarize pathologists with epidemiologic and histologic findings of HAV.

\title{
1454 Electron Microscopic Characteristics of Gallbladder Epithelial Inclusions Mimicking Cystoisospora - A Closure to The Cystoisospora Controversy
}

\author{
Aysha Mubeen ${ }^{1}$, Ahmad Alkhasawneh², Brett Baskovich², Amber Ginn ${ }^{1}$, Raafat Makary ${ }^{1}$, Amal Shukri ${ }^{1}$, Manuel Menes ${ }^{3}$, Kenneth \\ Kaylor $^{1}$, Shahla Masood ${ }^{1}$, Arun Gopinath ${ }^{1}$ \\ ${ }^{1}$ University of Florida College of Medicine, Jacksonville, FL, ${ }^{2}$ UF Health Jacksonville, Jacksonville, FL, ${ }^{3}$ University of Florida \\ College of Medicine, Coral Gables, FL
}

Disclosures: Aysha Mubeen: None; Ahmad Alkhasawneh: None; Brett Baskovich: None; Amber Ginn: None; Raafat Makary: None; Amal Shukri: None; Manuel Menes: None; Kenneth Kaylor: None; Shahla Masood: None; Arun Gopinath: None

Background: Several groups including ours have reported occurrence of Cystoisospora in gallbladders (GB) of immunocompetent people. These were more commonly seen in biliary dyskinesia (BD) patients compared to calculus cholecystitis. However, very recently Swanson et al performed molecular analysis targeting the internal transcribed spacer (ITS2) in the C. belli ribosomal gene in similar specimens. No amplification was found in the GB specimens as opposed to the positive Cytoisospora infected intestinal specimens from immunocompromised individuals. They suggested that these are epithelial inclusions comprising of cytoplasmic and nuclear material resulting from bile mediated cytolysis. In the current study, we are describing the ultra-structural details of Cystoisospora like inclusions in GB epithelium by electron microscopy.

Design: On review of 1850 consecutive cholecystectomy specimen from immunocompetent patients, we identified 25 cases of these epithelial structures. Two cases with diffuse involvement of the gallbladder epithelium were selected and the representative areas were cored out from the FFPE blocks and were submitted for EM analysis. Also, PCR based molecular analysis by using a primer mix for ITS1, ITS2, and the Universal $18 \mathrm{~S}$ primer for protozoa was performed on the samples.

Results: Electron microscopic analysis showed cytoplasmic condensations (Fig 1) leading to vacuolization and mimicking the micro and macrogamatocyte forms of Cystoisospora (Fig 2). In contrast to Cystoisospora, they did not have flagella or other well organized structures. In some of the inclusions, the central part is denser giving the appearance of a nucleus of a microgametocyte. The epithelial cell nuclei were preserved and no degenerated nuclear material was seen in the inclusions. None of these cases showed amplified products on molecular analysis.
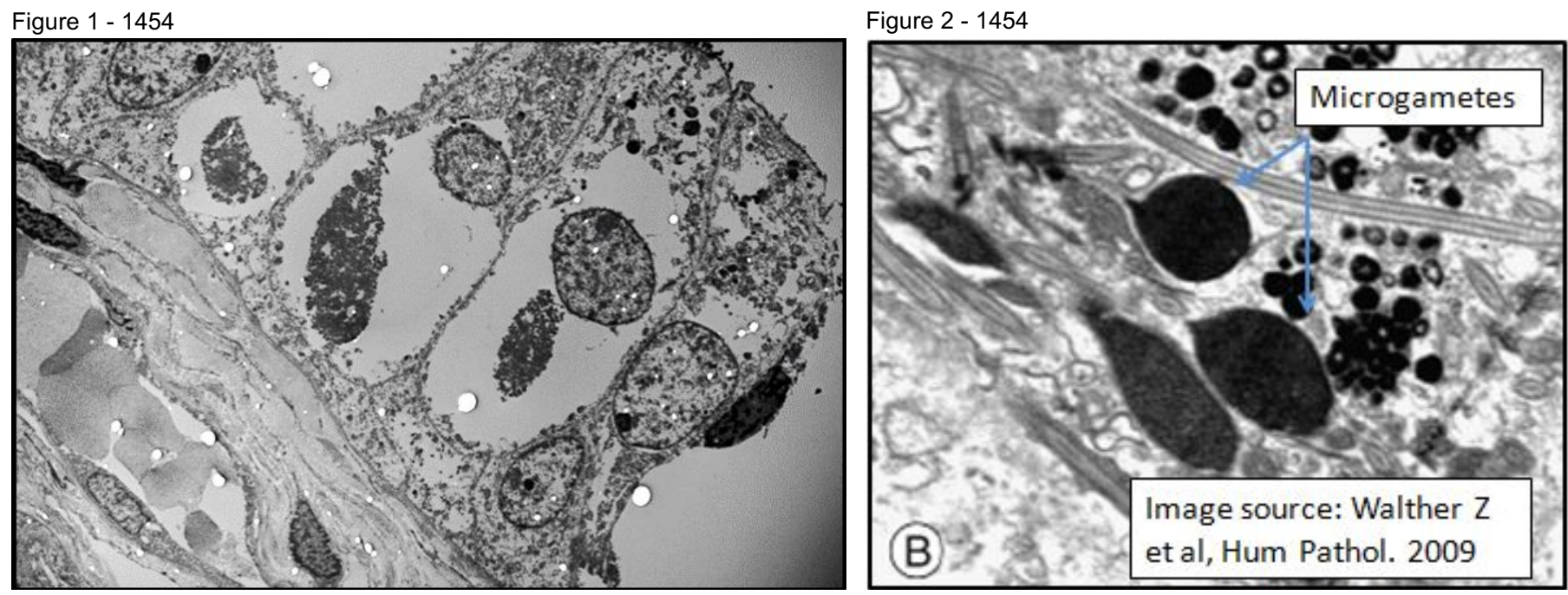

Conclusions: EM and molecular analysis reveals that these intraepithelial structures are inclusions formed by condensation of the cytoplasm and not of protozoan origin. Reduced ejection fraction in BD patients may lead to prolonged exposure of GB mucosa to bile (cytolytic) and more frequent development of these inclusions. However, prospective studies evaluating the role of preanalytic variables (time to formalin exposure of the gallbladder mucosa, different technical parameters involved in specimen processing etc.) in the development of these inclusions are needed. Awareness of these rare findings is necessary to avoid over-diagnosis of Cystoisospora infection. 


\section{Cysticercosis: Report of 10 Cases Diagnosed at a District Hospital in Rwanda}

Marcellin Mugabe1, Deogratias Ruhangaza², Emmanuel Hakizimana ${ }^{3}$, Nshimiyimana Irénée ${ }^{4}$

${ }^{1}$ Butaro Hospital/Butaro Cancer Center of Excellence, Kigali, Rwanda, ${ }^{2}$ Burera, Rwanda, ${ }^{3}$ Butaro Hospital/Butaro Cancer Center of Excellence, Burera, Rwanda, ${ }^{4}$ Butaro Hospital/Butaro Cancer Center of Excellence, Burera District, Rwanda

Disclosures: Marcellin Mugabe: None; Deogratias Ruhangaza: None; Emmanuel Hakizimana: None; Nshimiyimana Irénée: None

Background: Cysticercosis, From Ancient Greek kústis, "bladder" + kérkos, "tail", is the larval stage of the pork tapeworm (Tenia Solium) infection to the human beings. The infection is acquired through faecal-oral contamination with Tenia solium eggs from carriers.

Vegetarians and other people who do not eat pork can get infected. It was first described in 1555. Mainly cysticercosis affects skin, brain, muscle, and eye. It is most prevalent in South Asia, Sub-Saharan Africa, and Latin America. It is very uncommon in developed countries. In one study in 2013 in the south of Rwanda, 22\% of cases with epilepsy were associated with Neurocysticercosis (Ruth Rottbeck et Al). Anatomical Pathology service at Butaro District Hospital, the Cancer center of the Country, opened its services in 2013. We report 10 cases of cutaneous cysticercosis confirmed by histopathology.

Design: We conducted a retrospective search of cases with cysticercosis in the anatomical pathology department files from 2016 to 2018. We retrieved and reviewed slides. We confirmed the diagnosis for all cases.

Results: We identified 10 cases with cutaneous cysticercosis. All of them presented complaining of persistent skin nodules. 5 out 10 (50\%) were male. Their age were ranging from 2 months old to 65 years old. 4 out of $10(40 \%)$ presented with multiple nodules on different parts of the skin; the remaining presented with single nodules. For one case, five nodules were sampled and all of them contained cysticerci on histopathology examination.

5 out $10(50 \%)$ were from a single district in the south-western part of the country. Others were from different areas. One was from Burundi, a neighboring country. 5 of them were diagnosed in 2018, 3 in 2017 and 2 in 2016.

Conclusions: We document 10 cases of cysticercosis confirmed by histopathology in our service. A half of them (50\%) were from a single District, Nyamasheke, in Eastern Province, Rwanda. However, this number is too small to make an assumption that the region presents high prevalence of the disease compared to other areas of the country. A larger study with skin sampling of the skin lesions in the mentioned region would be more conclusive. This series of cases is adding to the knowledge about the disease to other published cases. Well cooked pork meat can prevent new infections. To all these cases with diagnosis of cystercosis cutis, CT scan and fundus examination were suggested to rule out/in any other associated brain and/or eye infection and orient the treatment accordingly.

\section{Incidence of CMV Colitis amongst IBD Patients - An Institutional Review}

Chirag Patel ${ }^{1}$, John Builes ${ }^{2}$, Zheng Ping ${ }^{3}$, Monica Garcia-Buitrago ${ }^{4}$

${ }^{1}$ University of Miami Miller School of Medicine/Jackson Memorial Hospital, Miami, FL, ${ }^{2}$ University of Miami, Coral Springs, GA, ${ }^{3}$ Vestavia, AL, ${ }^{4}$ University of Miami Miller School of Medicine/Jackson Health System, Miami, FL

Disclosures: Chirag Patel: None; John Builes: None; Zheng Ping: None; Monica Garcia-Buitrago: None

Background: Cytomegalovirus (CMV) infection often reactivates during exacerbations of inflammatory bowel disease (IBD), Crohn's disease (CD) and Ulcerative colitis (UC), and amongst immunocompromised patients. In our institution, the Gastrointestinal Department requested us to evaluate all the severe active chronic ileocolitis for CMV by immunohistochemistry (IHC). The aim of this study was to determine the incidence of CMV reactivation amongst our IBD patients and to assess the clinical importance of the CMV IHC results.

Design: Retrospective review of our database was performed searching for IBD patients with severe active colitis who underwent reflex evaluation for CMV infection in ileocolonic tissue by IHC, from September 2013 to September 2018. Clinical, pathological, and serological parameters (CMV-PCR) were analyzed in all CMV-positive patients.

Results: Over the five year period, 556 patients met the inclusion criteria. Of these, $8(1.4 \%)$ were noted to have CMV positive staining by IHC. Of the CMV positive patients, 5 had UC, 2 had CD, and 1 was deemed indeterminate colitis (IBD-NOS). Five of the patients showed CMV-PCR levels (ranging from 460 to 9903 copies IU/mL) detected in blood: 3 patients with UC, 1 with CD, and 1 with IBD-NOS. All five of these patients received successful anti-viral therapy and showed eradication on multiple follow-up tests. One patient with CMV positivity by $\mathrm{IHC}$ had what was clinically considered dormant disease as there was little clinical suspicion and the CMV-PCR was negative. Another patient had a recent biopsy diagnosis of CMV infection, confirmed by IHC, and is awaiting CMV-PCR results. Lastly, one patient underwent therapeutic colectomy for IBD and infectious colitis but was subsequently lost to follow-up. 


\begin{tabular}{|l|l|l|}
\hline & & CMV IHC positive \\
\hline IBD patients & 556 & $8(1.44 \%)$ \\
\hline Average Age & 44.3 & \\
\hline Male & $285(51.3 \%)$ & \\
\hline Crohn's disease & 296 & $2(0.68 \%)$ \\
\hline Average Age & 40.0 & \\
\hline Male & $148(50 \%)$ & \\
\hline Ulcerative Colitis & 189 & $5(2.65 \%)$ \\
\hline Average Age & 47.0 & \\
\hline Male & $95(50.3 \%)$ & \\
\hline IBD-NOS & 71 & $1(1.41 \%)$ \\
\hline Average Age & 51.5 & \\
\hline Male & $42(59.2 \%)$ & \\
\hline
\end{tabular}

Conclusions: Histologic and reflex IHC CMV testing is frequently performed on ileocolonic biopsies of patients with severe exacerbations of IBD. However, our institutional study demonstrates the extremely low rate of positivity for CMV ileocolitis in these patients $(1.4 \%)$. Of the 8 patients with CMV positivity by reflex IHC testing, five patients had detectable DNA on CMV-PCR studies (62.5\%) while only one patient tested was shown to have dormant disease $(12.5 \%)$ with no detectable DNA by CMV-PCR. The clinical application of reflex IHC testing for $\mathrm{CMV}$ is best utilized when there is high clinical suspicion. However, reflex testing provides the benefit of detecting dormant disease that requires further clinical workup in this immunocompromised population.

\section{Role of Fine-Needle Aspiration Cytology in Early Diagnosis of Fungal Infections}

Maria del Mar Rivera Rolon ${ }^{1}$, Ranjana Nawgiri ${ }^{2}$, Vicki Schnadig ${ }^{3}$, Cecilia Clement $^{2}$

${ }^{1}$ UTMB, Galveston, TX, ${ }^{2}$ University of Texas Medical Branch, Galveston, TX, ${ }^{3}$ Seabrook, TX

Disclosures: Maria del Mar Rivera Rolon: None; Ranjana Nawgiri: None; Vicki Schnadig: None; Cecilia Clement: None

Background: Fine-needle aspiration (FNA) is an important tool for the diagnosis of infectious diseases. This study assesses the utility of fine?needle aspiration cytology in early diagnosis of fungal infections.

Design: This is a retrospective study for the period January 2016 to August 2018. We searched our electronic archives for FNAs from superficial and deep lesions from various sites diagnosed as fungal infection. Each case was evaluated for: predisposing conditions, FNA site, radiologic findings, microbial culture along with serology results, and complications.

Results: Eight cases were identified, 4 were FNAs of cervical lymph nodes, 2 lung, 1 soft tissue, and 1 retroperitoneal lymph node. Predisposing conditions were found in six patients: 5 HIV and 1 malignancy. Differential diagnoses by imaging were malignancy and fungal infection. In all 8, the diagnosis of fungal infection was given on initial FNA examination, with correct specific genus in 7 (5 Histoplasma, 1 Cryptoccocus, and 1 Coccidioides). Four of these 8 cases were diagnosed within 24 hours (two at onsite evaluation). Microbial cultures were confirmatory in 4, negative cultures with positive serology in 3, and one case with a negative culture had a good clinical response to therapy for histoplasmosis. No major complications were seen. All patients were treated and discharged. 


\begin{tabular}{|c|c|c|c|c|c|c|c|c|c|}
\hline \multirow{2}{*}{$\begin{array}{l}\text { Cas } \\
\text { e\# }\end{array}$} & \multirow{2}{*}{$\begin{array}{l}\text { Age/se } \\
x\end{array}$} & \multirow{2}{*}{$\begin{array}{l}\text { Mode of } \\
\text { FNA/Site }\end{array}$} & \multirow{2}{*}{$\begin{array}{l}\text { Prediposin } \\
\text { g condition }\end{array}$} & \multirow[t]{2}{*}{ Radiology } & \multirow[t]{2}{*}{ Cytology dx } & \multicolumn{2}{|c|}{ Microbiology result } & \multirow[t]{2}{*}{ Serology } & \multirow[t]{2}{*}{ Follow up } \\
\hline & & & & & & Direct $\mathrm{KOH}$ & Culture & & \\
\hline 1 & $48 / \mathrm{M}$ & $\begin{array}{l}\text { Palpation/ } \\
\text { LN neck }\end{array}$ & HIV & $\begin{array}{l}\text { Numerous } \\
\text { enlarged LN } \\
\text { mediastinal, } \\
\text { both axillary, } \\
\text { suggestive } \\
\text { lymphoma. } \\
\text { Lesions in } \\
\text { lung: } \\
\text { infectious vs } \\
\text { neoplasm }\end{array}$ & $\begin{array}{l}\text { Cryptococcus } \\
\text { (diagnosed at } \\
\text { ROSE) }\end{array}$ & $\begin{array}{l}\text { Budding } \\
\text { yeasts }\end{array}$ & $\begin{array}{l}\text { Positive- } \\
\text { at day } 11\end{array}$ & $\begin{array}{l}\text { Cryptococcu } \\
\text { s Ag CSF } \\
(+)\end{array}$ & $\begin{array}{l}\text { Treated and } \\
\text { discharged in } 3 \\
\text { weeks fair condition }\end{array}$ \\
\hline 2 & $30 / \mathrm{M}$ & $\begin{array}{l}\text { US-FNA/ } \\
\text { LN } \\
\text { supraclavic. }\end{array}$ & HIV & $\begin{array}{l}\text { Lung nodules. } \\
\text { LAD } \\
\text { mediastinal. } \\
\text { Concern for } \\
\text { lymphoma or } \\
\text { other } \\
\text { malignancies; } \\
\text { infectious less } \\
\text { likely. }\end{array}$ & $\begin{array}{l}\text { Histoplasma } \\
\text { (diagnosed in } 2 \\
\text { days) }\end{array}$ & Yeast & $\begin{array}{l}\text { Positive- } \\
\text { at day } 8\end{array}$ & $\begin{array}{l}\text { Histoplasma } \\
\text { Ag urine }(+)\end{array}$ & $\begin{array}{l}\text { Treated and } \\
\text { discharged in } 2 \\
\text { weeks fair condition }\end{array}$ \\
\hline 3 & $34 / M$ & $\begin{array}{l}\text { Palpation / } \\
\text { LN neck }\end{array}$ & HIV & $\begin{array}{l}\text { CXR: lungs } \\
\text { clear }\end{array}$ & $\begin{array}{l}\text { Histoplasma } \\
\text { (diagnosed within } \\
24 \mathrm{~h} \text { ) }\end{array}$ & Negative & Negative & $\begin{array}{l}\text { Histoplasma } \\
\text { Ag } \\
\text { serum weak } \\
(+) \text {. Histo } \mathrm{Ag} \\
\text { urine (+) }\end{array}$ & $\begin{array}{l}\text { Treated and } \\
\text { discharged in } 2 \\
\text { weeks fair condition }\end{array}$ \\
\hline 4 & $70 / F$ & $\begin{array}{l}\text { EBUS-FNA } \\
\text { / Lung RML }\end{array}$ & NA & $\begin{array}{l}\text { Multilobar } \\
\text { consolidation } \\
\text { suggestive } \\
\text { infection. } \\
\text { Multiple lung } \\
\text { nodules, } \\
\text { malignancy } \\
\text { cannot be r/o }\end{array}$ & $\begin{array}{l}\text { Histoplasma } \\
\text { (diagnosed in } 5 \\
\text { days) }\end{array}$ & Negative & Negative & NA & $\begin{array}{l}\text { Treatment } \\
\text { ambulatory }\end{array}$ \\
\hline 5 & $30 / \mathrm{M}$ & $\begin{array}{l}\text { Palpation/L } \\
\mathrm{N} \\
\text { supraclavic }\end{array}$ & HIV & $\begin{array}{l}\text { Nonspecific } \\
\text { multiple lung } \\
\text { nodules. } \\
\text { Necrotic } \\
\text { supraclavicul } \\
\text { ar LN. }\end{array}$ & $\begin{array}{l}\text { Histoplasma } \\
\text { (diagnosed at } \\
\text { ROSE) }\end{array}$ & Negative & $\begin{array}{l}\text { Positive- } \\
\text { at day } 14\end{array}$ & $\begin{array}{l}\text { Histoplasma } \\
\text { Ag urine }(+)\end{array}$ & $\begin{array}{l}\text { Treated and } \\
\text { discharged in } 2 \\
\text { weeks fair condition }\end{array}$ \\
\hline 6 & $58 / \mathrm{M}$ & $\begin{array}{l}\text { US-FNA/ } \\
\text { Lung RUL }\end{array}$ & SqCC face & $\begin{array}{l}\text { Nonspecific } \\
\text { lung nodules, } \\
\text { infectious vs } \\
\text { mets } \\
\text { malignancy }\end{array}$ & $\begin{array}{l}\text { Fungal } \\
\text { yeasts Blastomyce } \\
\text { s vs Cryptococcus } \\
\text { (diagnosed within } \\
24 \mathrm{~h} \text { ) }\end{array}$ & $\begin{array}{l}\text { Mould/yea } \\
\text { st }\end{array}$ & Negative & $\begin{array}{l}\text { Cryptococcu } \\
\text { s Ag serum } \\
(+)\end{array}$ & $\begin{array}{l}\text { Treatment ambulato } \\
\text { ry }\end{array}$ \\
\hline 7 & $26 / \mathrm{M}$ & $\begin{array}{l}\text { Palpation / } \\
\text { Soft tissue } \\
\text { back }\end{array}$ & NA & $\begin{array}{l}\text { Paraspinal } \\
\text { abscesses } \\
\text { most c/w TB } \\
\text { or fungal. }\end{array}$ & $\begin{array}{l}\text { Coccidioides } \\
\text { (diagnosed in } 5 \\
\text { days) }\end{array}$ & Spherules & $\begin{array}{l}\text { Positive- } \\
\text { at day } 14\end{array}$ & $\begin{array}{l}\text { Coccidioides } \\
\text { Abs }(+)\end{array}$ & $\begin{array}{l}\text { Treated and } \\
\text { discharged in } 3 \\
\text { weeks fair condition }\end{array}$ \\
\hline 8 & $30 / \mathrm{M}$ & $\begin{array}{l}\text { US-FNA / } \\
\text { LN } \\
\text { retroperit }\end{array}$ & HIV & $\begin{array}{l}\text { Bowel } \\
\text { thickening, } \\
\text { retroperitonea } \\
\text { I and } \\
\text { mesenteric } \\
\text { LAD concern } \\
\text { lymphoma, } \\
\text { infection less } \\
\text { likely. }\end{array}$ & $\begin{array}{l}\text { Histoplasma } \\
\text { (diagnosed in } 3 \\
\text { days) }\end{array}$ & $\begin{array}{l}\text { Negative } \\
\text { for fungi. } \\
\text { AFB } \\
\text { positive 2+ }\end{array}$ & $\begin{array}{l}\text { Negative } \\
\text { for fungi. } \\
\text { Positive } \\
\text { for } \\
\text { mycobact } \\
\end{array}$ & $\begin{array}{l}\text { Histoplasma } \\
\text { Ag urine }(+)\end{array}$ & $\begin{array}{l}\text { Treated and } \\
\text { discharged in } 3 \\
\text { weeks fair condition }\end{array}$ \\
\hline & & & & & & & & & \\
\hline
\end{tabular}

Conclusions: FNA is a rapid, safe, and reliable method to establish an early diagnosis of fungal infections, allowing an early and appropriate management, especially in immunocompromised patients. Onsite evaluation can guide appropriate culture implementation. 


\section{Diagnostic and Therapeutic Utility of Procalcitonin in Various Infections: A Tertiary Care Center Experience}

Ayesha Siddique ${ }^{1}$, Jaber Aslanzadeh ${ }^{2}$, Eric Orelup ${ }^{2}$, Gregory Makowski ${ }^{2}$

${ }^{1}$ Rocky Hill, CT, ${ }^{2}$ Hartford Hospital, Hartford, CT

Disclosures: Ayesha Siddique: None; Jaber Aslanzadeh: None; Eric Orelup: None; Gregory Makowski: None

Background: Antibiotic use contributes to increasing bacterial resistance, medical costs and drug-related adverse events. Procalcitonin (PCT), a 116 amino-acid peptide-prohormone of calcitonin is secreted by a variety of cells in response to proinflammatory stimulation by bacterial toxins. Detection and monitoring of plasma/serum PCT is useful in sepsis/infection.

Design: This study compared the diagnostic utility of plasma/serum PCT measured by Elecsys BRAHMS PCT on Cobas $6000 / \mathrm{e} 601$ (Roche, Indianapolis, IN) versus traditional culture for predicting bacteremia/infection. A total of 537 consecutive medical records were reviewed for patients with concurrent PCT and blood/respiratory/urine/tissue/wound cultures. PCT values were divided into $<0.09 \mathrm{ng} / \mathrm{ml}$ (negative/rule out infection), $\geq 0.09-<0.25 \mathrm{ng} / \mathrm{ml}$ (indeterminate) and $\geq 0.25 \mathrm{ng} / \mathrm{ml}$ (positive/probable infection). The patients were analyzed as a complete group as well as stratified according to the type of positive cultures. The patients were also stratified according to gram positive and negative organisms.

Results: Out of 537 patients, 309 (57.5\%) were males and 228 (42.5\%) females. The age range was $24-101$ years. Eighty-nine patients had a PCT $<0.09 \mathrm{ng} / \mathrm{ml}$. Of these, 3 patients showed isolates on blood, 6 on respiratory and 11 on urine cultures. One-hundred-and-forty patients had indeterminate PCT with 4 isolates on blood culture, 4 on respiratory and 14 on urine. Three-hundred-and-eight patients had a $\mathrm{PCT} \geq 0.25 \mathrm{ng} / \mathrm{ml}$ with 46 isolates on blood, 16 on respiratory, 39 on urine, 4 on wound and 1 on tissue culture. The antibiotic administration prior to culture collection was $55.5 \%$ in PCT $<0.25 \mathrm{ng} / \mathrm{ml}$ group and $30.8 \%$ in PCT $\geq 0.25 \mathrm{ng} / \mathrm{ml}$ group. (Table 1 )

In the PCT $\geq 0.25 \mathrm{ng} / \mathrm{ml}$ group 95/308 patients received an antibiotic prior to culture specimen collection. Of the remaining 213 patients, 23 isolates were found on blood, 12 on respiratory, 21 on urine, 4 on wound and 1 on tissue culture. (Table2a). PCT ranges and means stratified by the type of organism are listed in Table2b.

The sensitivity and negative predictive values of PCT were $84.1 \%$ and $77.6 \%$ while the specificity and positive predictive values were $34.1 \%$ and $34.4 \%$ respectively.

\begin{tabular}{|c|c|c|c|c|c|c|c|}
\hline $\begin{array}{l}\text { Procalcitonin } \\
\text { (ng/ml) }\end{array}$ & $\begin{array}{l}\text { No. of } \\
\text { patients }\end{array}$ & $\begin{array}{l}\text { Patients } \\
\text { with } \\
\text { antibiotics } \\
\text { before } \\
\text { culture } \\
\text { collected }\end{array}$ & Blood culture & $\begin{array}{l}\text { Respiratory } \\
\text { culture }\end{array}$ & Urine culture & $\begin{array}{l}\text { Wound } \\
\text { culture }\end{array}$ & $\begin{array}{l}\text { Tissue } \\
\text { culture }\end{array}$ \\
\hline$<0.09$ & 89 & 32 & $\begin{array}{l}1 \text { Corynebacterium } \\
1 \mathrm{~S} \text { epidermidis } \\
1 \mathrm{MRSA}\end{array}$ & $\begin{array}{l}2 \mathrm{~S} \text { aureus } \\
2 \mathrm{P} \text { aeruginosa } \\
1 \mathrm{MRSA} \\
1 \mathrm{~S} \text { marcescens }\end{array}$ & $\begin{array}{l}2 \text { E coli } \\
3 \mathrm{~K} \text { pneumoniae } \\
1 \mathrm{STN} \\
1 \mathrm{M} \text { morgagni } \\
2 \text { citrobacter } \\
2 \text { Lactobacillus }\end{array}$ & None & None \\
\hline$\geq 0.09-<0.25$ & 140 & 95 & $\begin{array}{l}\text { 1 C parapsilosis } \\
2 \mathrm{MRSA} \\
1 \mathrm{~S} \text { hominis }\end{array}$ & $\begin{array}{l}1 \mathrm{E} \text { aerogenes } \\
1 \mathrm{E} \text { cloacae } \\
1 \mathrm{~K} \text { pneumoniae } \\
1 \mathrm{~S} \text { aureus }\end{array}$ & $\begin{array}{l}2 \text { Lactobacillus } \\
1 \text { E cloacae } \\
2 \text { E coli } \\
2 \text { E faecalis } \\
2 \text { Citrobacter } \\
2 \text { K pneumoniae } \\
1 \text { P aeruginosa } \\
1 \text { Pantoea species } \\
1 \text { E coli }\end{array}$ & None & None \\
\hline$\geq 0.25$ & 308 & 95 & $\begin{array}{l}4 \mathrm{~S} \text { epidermidis } \\
2 \text { Group B streptococcus } \\
1 \text { C glabrata } \\
1 \mathrm{~S} \text { capitis } \\
2 \mathrm{C} \text { difficile } \\
8 \mathrm{~S} \text { aureus } \\
5 \mathrm{MRSA} \\
3 \mathrm{~S} \text { viridans } \\
1 \mathrm{VRE} \\
2 \mathrm{E} \text { faecalis } \\
1 \mathrm{~S} \text { hominis } \\
2 \mathrm{P} \text { mirabilis } \\
5 \mathrm{E} \text { coli } \\
1 \mathrm{STN} \\
1 \text { clostridium species } \\
1 \mathrm{H} \text { influenzae } \\
2 \mathrm{P} \text { aeruginosa } \\
2 \mathrm{~S} \text { auricularis } \\
1 \mathrm{~K} \text { pneumoniae } \\
1 \text { Enterobacter species }\end{array}$ & $\begin{array}{l}2 \mathrm{~S} \text { aureus } \\
1 \mathrm{~K} \text { oxytoca } \\
2 \mathrm{H} \text { influenzae } \\
2 \mathrm{MRSA} \\
5 \mathrm{P} \text { aeruginosa } \\
1 \mathrm{~K} \text { pneumoniae } \\
1 \mathrm{E} \text { cloacae } \\
1 \mathrm{E} \text { coli } \\
1 \mathrm{C} \text { striatum }\end{array}$ & $\begin{array}{l}1 \mathrm{~S} \text { epidermidis } \\
13 \mathrm{E} \text { coli } \\
4 \mathrm{~S} \text { aureus } \\
2 \mathrm{P} \text { aeruginosa } \\
4 \mathrm{~K} \text { oxytoca } \\
5 \mathrm{P} \text { mirabilis } \\
1 \mathrm{E} \text { faecium } \\
3 \mathrm{E} \text { faecalis } \\
1 \mathrm{E} \text { cloacae } \\
3 \mathrm{~K} \text { pneumoniae } \\
1 \mathrm{MRSA} \\
1 \text { corynebacterium }\end{array}$ & $\begin{array}{l}2 \mathrm{~S} \text { aureus } \\
1 \mathrm{P} \\
\text { aeruginosa } \\
1 \mathrm{~S} \\
\text { marcescens }\end{array}$ & $\begin{array}{l}1 \mathrm{~S} \\
\text { viridans }\end{array}$ \\
\hline
\end{tabular}


Figure $1-1458$

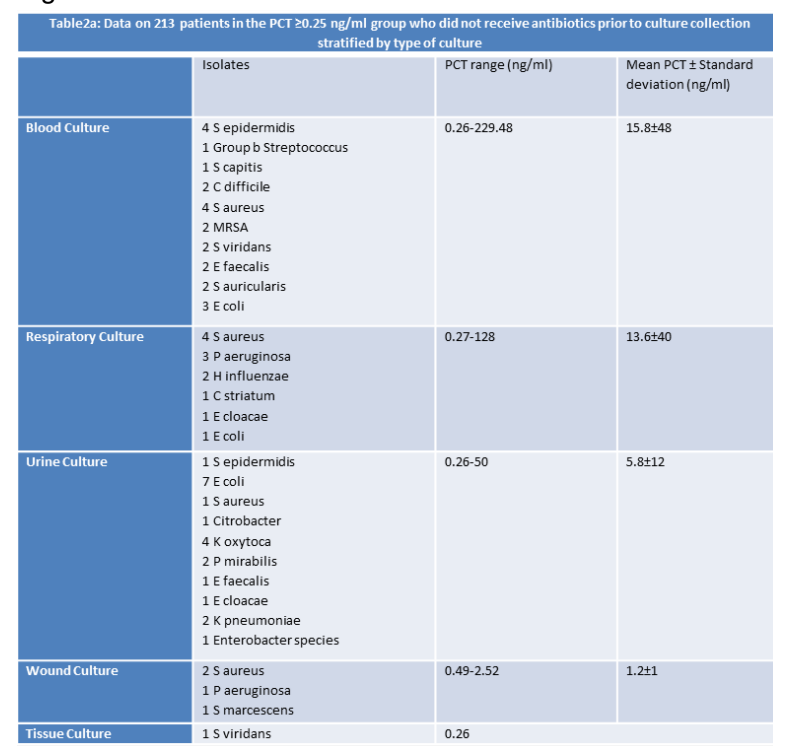

Figure 2 - 1458

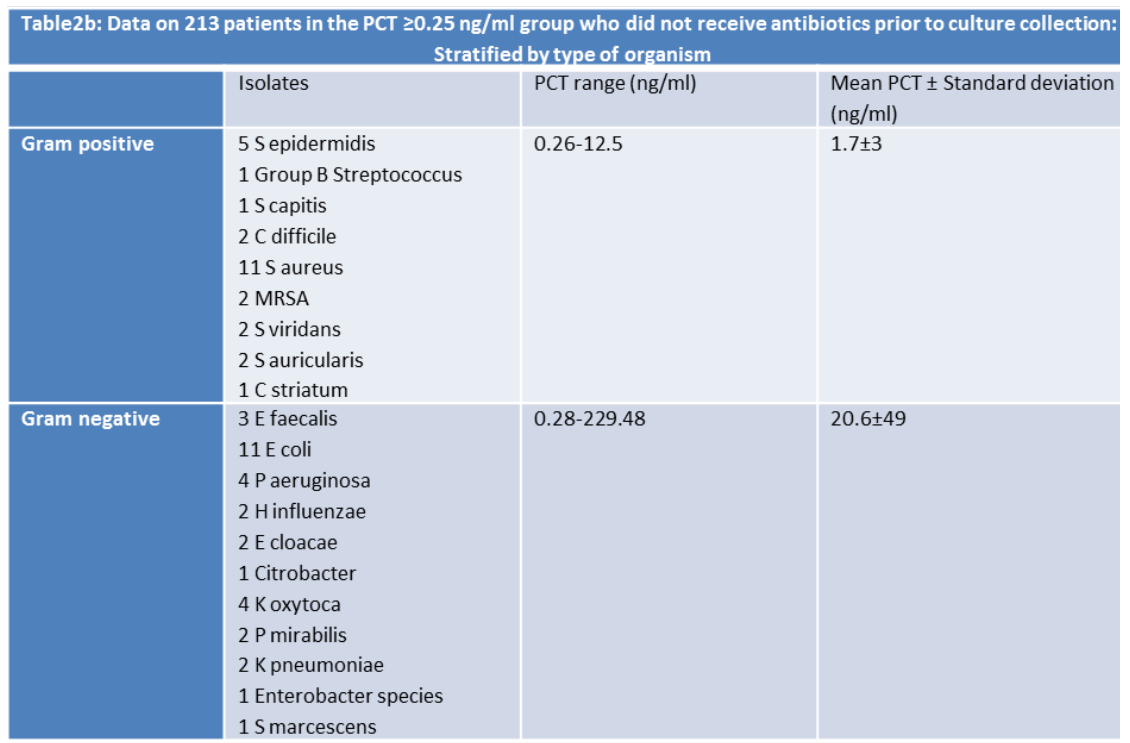

Conclusions: PCT had a very good diagnostic sensitivity $(84.1 \%)$ and NPV $(77.6 \%)$ in ruling out infection. Despite the high sensitivity, the antibiotic use in the PCT $<0.25 \mathrm{ng} / \mathrm{ml}$ group was higher $(p<0.05)$ than $\mathrm{PCT} \geq 0.25 \mathrm{ng} / \mathrm{ml}$ group. Mean PCT levels were significantly higher for gram negative organisms than gram positives $(p=0.04)$.

\section{Identification of Helicobacter pylori Organisms by Digital Image Analysis}

Mark Valasek ${ }^{1}$, Eli Brazowski², Yaron Anavi ${ }^{3}$, Ifat Rotbein ${ }^{4}$, Lotan Chorev $^{3}$, Eliron Amir ${ }^{4}$

${ }^{1}$ University of California, San Diego, La Jolla, CA, ${ }^{2}$ Jerusalem, Israel, ${ }^{3}$ Nucleai Ltd, Tel Aviv, Israel, ${ }^{4}$ Nucleai Ltd, Kfar Saba, Israel

Disclosures: Mark Valasek: Consultant, Nucleai Ltd; Eli Brazowski: Consultant, Nucleai Ltd; Yaron Anavi: Employee, Nucleai Ltd; Ifat Rotbein: Employee, Nucleai Ltd; Lotan Chorev: Employee, Nucleai Ltd; Eliron Amir: Major Shareholder, Nucleai Ltd

Background: Diagnosis of Helicobacter pylori (HP) infection routinely occurs via identification of organisms during histopathological evaluation of stomach biopsies or resection specimens. In addition to H\&E stains, various special stains or immunohistochemistry can be utilized to enhance sensitivity and specificity of detection, but these methods can be costly. Here, we explore the potential of digital image analysis (DIA) to aid in the identification of HP in H\&E stained pathological tissue specimens.

Design: We trained an artificial intelligence DIA algorithm based on convolutional neural networks (Nucleai-HP-Algorithm) using 35 H\&E slides to identify Helicobacter pylori (HP) organisms. A test image set of 80 cases (including both gastric biopsies and surgical resection specimens) was utilized and included the following diagnoses: 1) normal gastric mucosa or chronic gastritis/reactive gastropathy, HP negative ( $n=24), 2$ ) chronic gastritis, HP positive $(n=48)$, and 3) HP difficult to determine ( $=8)$. Two methods were used to evaluate HP: 1) whole slide (tissue biopsy) HP detection, or 2) within slide (within tissue biopsy) patch HP detection (1 patch = 22.5 um $\times 22.5$ um) to assist in locating the HP within a slide.

Results: The overall concordance between DIA and the reference pathologist was $91.7 \%$. Slide level sensitivity is $97.9 \%$ and specificity is $79.9 \%$. When the patch level is set at $80 \%$ sensitivity this leads to an average of 7 false positive areas (less than $0.01 \%$ of tissue surface area) for a gastric biopsy slide (where an area is defined as a group of patches with a distance up to 11.25um). Discrepancies include surgical specimens where there is a large amount of tissue or non-gastric tissue types.

Conclusions: The findings demonstrate the capability of DIA to successfully identify HP organisms in gastric tissue samples. Therefore, DIA may have a potential role to reduce time spent by pathologists on HP detection, reduce the need for use of ancillary testing (including IHC stains) or to be utilized in quality assurance/quality control measures. Future improvements of the algorithm can include training with larger data sets with more variety, which will improve performance. In addition, similar algorithms can identify signet ring cells in gastric samples. 


\section{An Unexpected Differential Diagnosis for Testicular Tumor: Paracoccidiodomycosis}

Pillar Venzon ${ }^{1}$, Ariane Haagsma², Ana Carolina Rodrigues ${ }^{3}$, I-Ching Lee ${ }^{1}$, Pietro Cantú ${ }^{3}$, Sara Kretzer ${ }^{4}$, Marta Vainchenker ${ }^{5}$, Daniella Vieira $^{6}$, Desiree Lovera Castedo ${ }^{1}$, João Péricles Silva Junior ${ }^{1}$, Ana Paula Pasinato ${ }^{3}$, Carlos Otavio Goncalves ${ }^{7}$

${ }^{1}$ Universidade Federal de Santa Catarina, Florianópolis, SC, Brazil, ${ }^{2}$ Palhovßa, SC, Brazil, ${ }^{3}$ Hospital Polydoro Ernani de São Thiago HU/UFSC, Florianópolis, SC, Brazil, ${ }^{4}$ Polydoro Ernani de São Thiago Hospital HU/UFSC, Florianópolis, SC, Brazil, ${ }^{5}$ nstituto de Anatomia Patológica, Florianópolis, SC, Brazil, "'Hospital Polydoro Ernani de São Thiago HU/UFSC, São Jose, SC, Brazil, ${ }^{7}$ Medicina Diagnóstica São Lucas, Tubarao, SC, Brazil

Disclosures: Pillar Venzon: None; Ariane Haagsma: None; Ana Carolina Rodrigues: None; I-Ching Lee: None; Pietro Cantú: None; Sara Kretzer: None; Marta Vainchenker: None; Daniella Vieira: None; Desiree Lovera Castedo: None; João Péricles Silva Junior: None; Ana Paula Pasinato: None; Carlos Otavio Goncalves: None

Background: There are many lesions capable of mimicking testicular or paratesticular neoplasms, occurring in around $6 \%$ to $30 \%$ of the cases. Possible causes include: vascular or inflammatory lesions, cysts and ectopic tissues. In the particular case of inflammatory lesions, which are represented by granulomatous disease, the main etiological agents are Mycobacterium tuberculosis, Brucella sp., Treponema pallidum, fungi and parasites.

Design: We present a case of a 67-year-old male patient from a rural area in Brazil, with a hardened mass on the right testicle. Orchiectomy was performed and the gross specimen consisted on a testicle weighing $60 \mathrm{~g}$ with a homogeneous, whitish solid nodule measuring 4,0 × 3,0 × 2,3 cm. Histologic examination showed a chronic inflammatory process with suppurative granulomatous reaction. Ziehl-Nelseen stain for mycobacteria resulted negative, but periodic acid-Schiff (PAS) and Grocott methenamine silver (GMS) stain revealed globose cells surrounded by multiple budding yeast cells, exhibiting the characteristic "steering wheel" appearance of Paracoccidioides brasiliensis. There was no evidence of neoplastic lesions on the specimen.

Results: Figure 1: Extensive granulomatous reaction in testicular interstitium - H\&E 40x.

Figure 2: (A) Chronic inflammatory process with suppurative granulomas with fungi (arrow) - H\&E 200x. (B) Paracoccidioides brasiliensis' multiple steering-wheel-shaped, budding yeast cells - PAS 1000x. (C) Globose large cell surrounded by narrow-necked budding yeast - GMS 1000x.
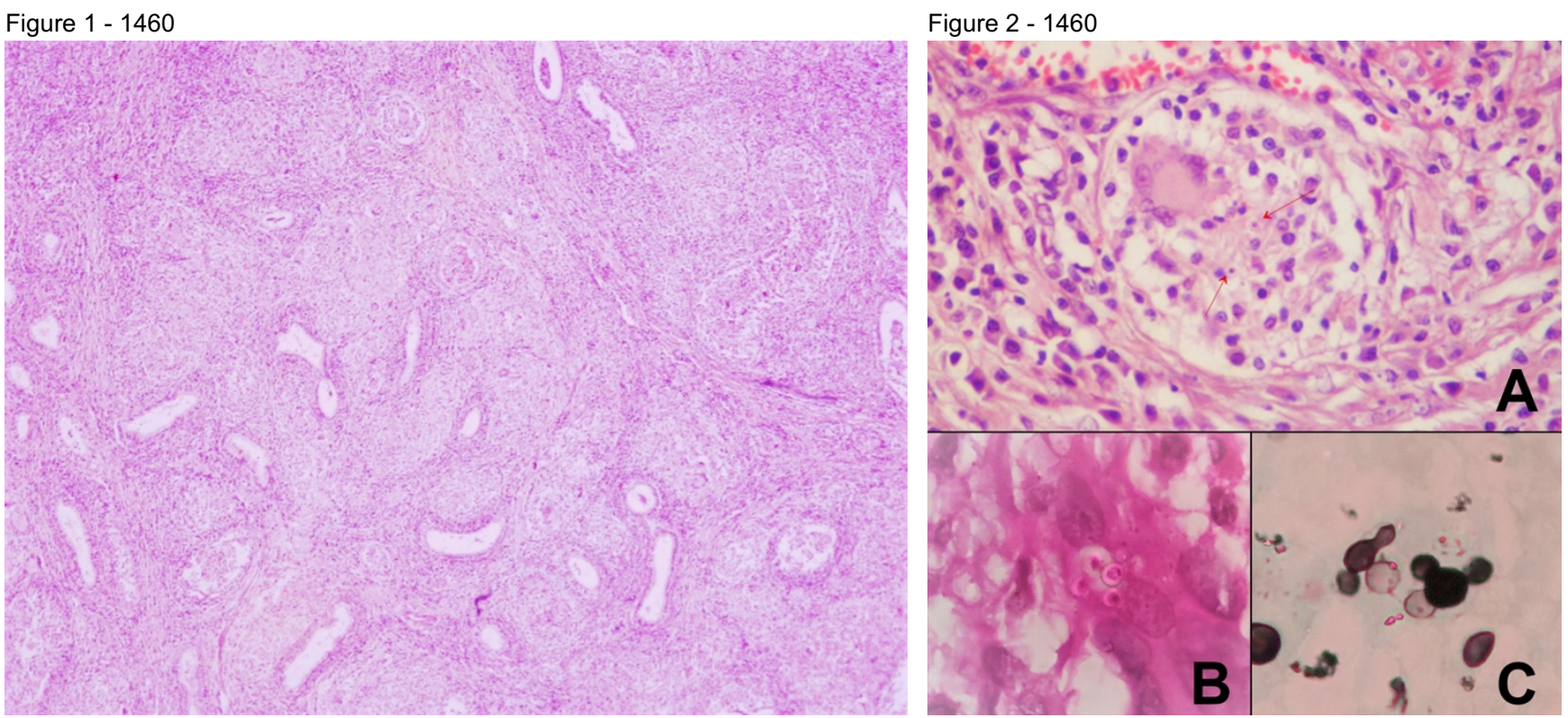

Conclusions: Paracoccidioidomycosis is an underdiagnosed disease, yet paradoxically it is the most prevalent systemic mycosis in Latin America. A review of the literature seems to indicate that only rare reports of paracoccidioidomycosis in the testicular and urological regions have been described in Brazil, most of them indigenous. There seem to be no cases reported in Anglo-Saxon countries. Another important issue to be considered is the legal implications of an orchiectomy in an illness potentially treatable with only clinical management. 


\section{Next Generation 16S rRNA Metagenomic Sequencing (NGS) Confirms the Utility of PCR based Urinary Tract Infection (UTI) Analysis in Identifying Significant Uropathogens}

Kirk Wojno ${ }^{1}$, Erik Avaniss-Aghajani ${ }^{2}$, Howard Korman ${ }^{1}$, Frank Burks ${ }^{1}$, Natalie Luke ${ }^{3}$, Colleen Kelly ${ }^{4}$, Patrick Keating ${ }^{1}$, Stephany Hindo ${ }^{1}$, Dylan Hazelton ${ }^{5}$, David Baunoch ${ }^{6}$, Michael Opel ${ }^{6}$, Miguel Penaranda ${ }^{6}$, Larry Sirls ${ }^{1}$, Sevana Yaghoubian ${ }^{2}$ ${ }^{1}$ Comprehensive Urology/Michigan Healthcare Professionals, Royal Oak, MI, ${ }^{2}$ Primex Clinical Laboratories, Inc, Van Nuys, CA, ${ }^{3}$ Pathnostics, Harrison TWP, MI, ${ }^{4}$ Kelly Statistical Consulting, Carlsbad, CA, ${ }^{5}$ Comprehensive Urology/Michigan Healthcare Professionals, Warren, MI, ${ }^{6}$ Pathnostics, Irvine, CA

Disclosures: Kirk Wojno: Primary Investigator, Pathnostics; Consultant, Pathnostics; Erik Avaniss-Aghajani: None; Howard Korman: Grant or Research Support, Pathnostics; Frank Burks: None; Natalie Luke: Employee, Pathnostics; Colleen Kelly: None; Patrick Keating: None; Stephany Hindo: None; Dylan Hazelton: None; David Baunoch: Employee, Pathnostics; Michael Opel: Consultant, Pathnostics; Miguel Penaranda: None; Larry Sirls: None; Sevana Yaghoubian: None

Background: Traditional urine cultures are fraught with significant challenges including; limited clean collection methods, difficulty working up polymicrobial infections, challenges in growing fastidious organisms, and prolonged TAT. Multiplex PCR is capable detecting and accurately quantify bacterial, viral and fungal organisms. We sought out to determine if multiplex PCR can accurately detect and quantify 42 pathogens present in the urine of symptomatic patients. We then used Next Generation 16S rRNA Metagenomic Sequencing to confirm the presence of uropathogens detected by the PCR assay and to identify organisms that may not have been detected by urine cultures.

Design: A retrospective review of 613 patients with lower urinary tracts symptoms over age 60 who had a commercially available PCR based molecular UTI test were used for this study. All patients had traditional microbiology urine cultures run in parallel and 100 patients underwent NGS of their samples. The study was designed and powered to show better than $85 \%$ positive percentage agreement with culture for significant uropathogen detection. NGS was used to adjudicate the results in 100 patients in effort to develop a reasonable gold standard for future studies.

Results: The 613 patients were classified by the urologist into the following cohorts based on clinical symptomatology; 582 cystitis, 28 prostatitis, and 2 interstitial cystitis. The cystitis group had a median age of 77 and a male to female ratio of $6: 4$. The most common presenting symptom was burning on urination in $37 \%$ of patients. There was $90.1 \%$ positive percentage agreement between the PCR and culture results, which significantly exceeded the non-inferiority threshold of $85 \%$ with $p=0.03 .22 \%$ of cases had significant levels of organisms that were detected by PCR that were missed on traditional culture, and these results were confirmed by NGS in a large number of cases. 75 cases of NGS have been completed and show excellent confirmation of the PCR results: $3 / 3=100 \%$ of culture positive, PCR negative samples were shown to be negative with NGS; $10 / 12=83 \%$ of culture negative, PCR positive samples were shown to be positive with NGS.

Conclusions: PCR based UTI analysis can detect significantly more organisms than traditional culture, and is significantly non-inferior in detecting the same organisms as traditional culture. Prospective randomized trials are currently underway that will be required to demonstrate a benefit to detecting and treating these additional organisms in patients.

\section{What is the best diagnostic modality for Blastomycosis Dermatitis in the endemic areas? An investigation in the green mountain state}

Ramin Zargham ${ }^{1}$, Allison Ciolino ${ }^{1}$, Michael Waisberg ${ }^{2}$, Christina Wojewoda ${ }^{3}$

${ }^{1}$ University of Vermont Medical Center, Burlington, VT, ${ }^{2}$ Henderson, NV, ${ }^{3}$ Essex Junction, VT

Disclosures: Ramin Zargham: None;' Allison Ciolino: None

Background: The diagnosis of blastomycosis is challenging. The diagnosis may be confirmed by histologic examination, microbiology cultures or urine antigen detection. Misdiagnosis is relatively common and appears multifactorial. In this study we attempt to uncover common risk factors. We also aim to investigate diagnostic challenges including the most sensitive method of detection in order to avoid treatment delays and possible misdiagnosis.

Design: A retrospective study was performed evaluating all cases of blastomycosis diagnosed at the University of Vermont Medical Center over ten years (2007-2017). Data concerning surgical pathology, cytopathology, autopsy, bone marrow and culture reports were obtained for all positive blastomycosis cases. Age and county matched control groups, representing $3 x$ the number of positive specimens, were obtained for comparison. 115 positive specimens, representing 57 patients with the average age of 51 years old, were identified.

Results: Our demographic data shows that the there is a higher incidence in males versus females (60\% vs $40 \%$ respectively). While $83 \%$ of patients with blastomycosis had a BMI over 28 , just $26 \%$ of the control group had this BMI range. The highest concentration of cases is around the Lake Champlain area. All 115 specimens were reviewed to determine the concordance of pathology and culture results. In our positive anatomic pathology cases, $25 \%$ had a negative culture report ( $5 \%$ of anatomic pathology specimens were not cultured).

Alternatively, $27 \%$ of cases with positive cultures, showed no Blastomyces in anatomic pathology specimens (13\% of these cases did not have any anatomic pathology specimen). 


\section{ABSTRACTS | INFECTIOUS DISEASE PATHOLOGY}

Conclusions: In conclusion, our data provides both demographic and clinical information and investigates possible risk factors associated with acquiring Blastomyces. In addition, our data elucidates how all detection modalities for such a life threatening infection are incomplete and can miss the diagnosis at a rate of $27 \%$ for anatomic pathology approach alone and $25 \%$ for microbiology cultures alone. Authors suggest that any of these methods of detection, especially in endemic areas and in individuals with the above-mentioned risk factors, should not be done as a single modality as there is a high possibility of misdiagnosis if any of these methods are used alone.Our animal data is in progress to compare with our human data and investigate the feasibility of suggesting the same methods of detection in animals with known symptoms to our veterinarian colleagues. 